\title{
Dopamine Restores Limbic Memory Loss, Dendritic Spine Structure, and NMDAR-Dependent LTD in the Nucleus Accumbens of Alcohol-Withdrawn Rats
}

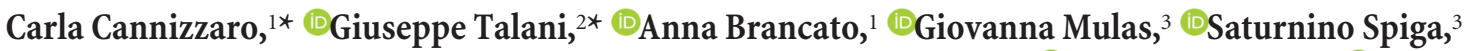 \\ Maria Antonietta De Luca, ${ }^{4}$ Angela Sanna, ${ }^{5}$ Rosa Anna Maria Marino, ${ }^{6}$ @ Giovanni Biggio, ${ }^{2,3}$ @Enrico Sanna, ${ }^{2,3}$ \\ and $\mathbb{Q}^{\text {Marco Diana }}{ }^{7}$ \\ ${ }^{1}$ Laboratory of Neuropsychopharmacology, Department ProSaMI G. D’Alessandro, University of Palermo, Via del Vespro 129 90127, Palermo, Italy, \\ ${ }^{2}$ Institute of Neuroscience, National Research Council, 09042 Monserrato, Cagliari, Italy, ${ }^{3}$ Department of Life and Environmental Sciences, Section of \\ Neuroscience and Anthropology, University of Cagliari, 09042 Monserrato, Cagliari, Italy, ${ }^{4}$ Department of Biomedical Sciences, Section of \\ Neuropsychopharmacology, University of Cagliari, Cittadella Universitaria-S.P., 09042 Monserrato, Cagliari, Italy, ${ }^{5}$ Department of Medical Science and \\ Public Health, University of Cagliari, Cittadella Universitaria-S.P., 09042 Monserrato, Cagliari, Italy, ${ }^{6}$ Intramural Research Program, National Institute on \\ Drug Abuse, National Institutes of Health, Baltimore, Maryland 21224, and 7University of Sassari, G.Minardi Laboratory of Cognitive Neuroscience, \\ Department of Chemistry and Pharmacy Via Muroni, 2307100 Sassari, Italy
}

Alcohol abuse leads to aberrant forms of emotionally salient memory, i.e., limbic memory, that promote escalated alcohol consumption and relapse. Accordingly, activity-dependent structural abnormalities are likely to contribute to synaptic dysfunctions that occur from suddenly ceasing chronic alcohol consumption. Here we show that alcohol-dependent male rats fail to perform an emotional-learning task during abstinence but recover their functioning by L-3,4-dihydroxyphenylalanin (L-DOPA) administration during early withdrawal. L-DOPA also reverses the selective loss of dendritic "long thin" spines observed in medium spiny neurons of the nucleus accumbens (NAc) shell of alcohol-dependent rats during abstinence, as well as the reduction in tyrosine hydroxylase immunostaining and postsynaptic density-95-positive elements. Patchclamp experiments in NAc slices reveal that both in vivo systemic L-DOPA administration and in vitro exposure to dopamine can restore the loss of long-term depression (LTD) formation, counteract the reduction in NMDAR-mediated synaptic currents and rectify the altered NMDAR/ AMPAR ratio observed in alcohol-withdrawn rats. Further, in vivo microdialysis experiments show that blunted dopaminergic signaling is revived after L-DOPA treatment during early withdrawal. These results suggest a key role of an efficient dopamine signaling for maintaining, and restore, neural trophism, NMDA-dependent LTD, and ultimately optimal learning.

Key words: alcohol abuse; confocal microscopy; dopamine; glutamate; LTD; memory

Significance Statement

Blunted dopamine signaling and altered glutamate connectivity in the nucleus accumbens represent the neuroanatomical basis for the impairment in aversive limbic memory observed during withdrawal in alcohol dependence. Supplying L-DOPA during withdrawal re-establishes synaptic morphology and functional neuroadaptations, suggesting a complete recovery of nucleus accumbens glutamatergic synaptic plasticity when dopamine is revived. Importantly, restoring dopamine transmission allows those synapses to encode emotionally relevant information and rescue flexibility in the neuronal circuits that process limbic memory formation. Under these conditions, drugs capable of selectively boosting the dopaminergic function during the "fluid" and still responsive state of the early withdrawn maladaptive synapses may help in the treatment of alcohol addiction.

\section{Introduction}

Alcohol withdrawal is associated with a series of negative affective symptoms whose occurrence, as negative reinforcement, in- creases the motivation for relapse and, in turn, favors the maintenance of addiction (Koob and LeMoal, 2001; Heilig et al.,

unpublished reagents/analytic tools; C.C., G.T., A.B., G.M.,S.S., M.A.D.L., A.S., R.A.M.M., G.B., and E.S. analyzed data; C.C., E.S., and M.D. wrote the paper.

This work was supported by the Fondazione Banco di Sardegna U1077.2015/AI.961.BE, CNR-DISVA-Sardegna Ricerche, Gieffe Supermercati, and Region of Sicily, Department of Family, Social Policies and Job, In-dependent Generation Grant. 
2010). A substantial body of work indicates that aberrant dopaminergic (DAergic) and glutamatergic-based plasticity in the mesocorticolimbic reward system plays a critical role in alcohol addiction and relapse (Koob and Volkow, 2010).

As a key component of the reward circuitry, the nucleus accumbens (NAc) is critical in the development of addiction. It receives DAergic signaling from the ventral tegmental area (VTA), as well as robust glutamatergic innervations from prefrontal cortex, hippocampus, amygdala, and the thalamus, converging on a common postsynaptic target, the striatal medium spiny neuron (MSN). Here, dendritic spines show a peculiar synaptic arrangement, called the "striatal microcircuit" or "synaptic triad" (Freund et al., 1984; Carr and Sesack, 1996). Alcohol dependence may affect the plasticity in the NAc synaptic triad architecture (Hyman et al., 2006; Kauer and Malenka, 2007; Gass and Olive, 2008; Kalivas and Volkow, 2011) including changes in density and head size of dendritic spines (Zhou et al., 2007; Uys et al., 2016). Accordingly, previous research had found signs of aberrant plasticity on MSNs of alcohol-withdrawn rats, evidenced by the simultaneous visualization of reduced DAergic projections [tyrosine hydroxylase (TH)], postsynaptic density scaffold (PSD95), and the selective remodeling of dendritic spine architecture (Spiga et al., 2014). Such changes are in agreement with a reduction in VTA DAergic firing rate in withdrawn rats (Diana et al., 1993; Rothblat et al., 2001) and strengthen the view of a link between synaptic indices of remodeling and the dampening in dopamine (DA) signaling (Diana et al., 1993; Weiss et al., 1996). Further, recent works (Lendvai et al., 2000; Kasai et al., 2010; Bosch et al., 2014; Berry and Nedivi, 2017) suggest a potential relationship between spine shape's rearrangement and synaptic dynamic response, as forms of experience-dependent plasticity (Trachtenberg et al., 2002) underpinning cellular learning (Bourne and Harris, 2007). Hence, the molecular, neuronal, and structural changes occurring during the development of addiction share similarities with those of physiological learning (Kiefer and Dinter, 2013). Moreover, the brain reward regions (VTA and NAc) potently influence behavioral memory through a direct involvement of DA neurons (Nestler, 2013). Indeed, DA neurons undergo experience-dependent synaptic plasticity during aversive experiences presumably by adding specific emotional weight and play a main role in the early stabilization of the memory trace of fear-related learning (Pignatelli et al., 2017). Accordingly, recovery of DA signaling in the striatum of DA-deficient mice was necessary to enable them to learn two-way active avoidance, by restoring synaptic strength (Darvas et al., 2011). Notably persistent impairment in synaptic strength, such as occluded long-term depression (LTD), could explain the loss of control on alcohol intake and relapse observed in addicted rodents (Ma et al., 2018). Putting the puzzle together, alcohol dependence, by dampening DAergic transmission, hijacks synaptic plasticity rules in the striatal network, and this can result in aberrant forms of emotionally salient memory, i.e., limbic memory, that may promote alcohol dependence. It follows that if we could rectify the alterations in the neuronal network connectivity associated to alcohol withdrawal, we would restore adaptive forms of functional and behavioral plasticity. This compelling theory was challenged by the present investigation, which focuses on the impact of a restored

The authors declare no competing financial interests.

${ }^{*}$ C.C. and G.T. contributed equally to this work.

Correspondence should be addressed to Marco Diana at dsfdiana@uniss.it.

https://doi.org/10.1523/JNEUROSCl.1377-18.2018

Copyright $\odot 2019$ the authors $\quad 0270-6474 / 19 / 390930-15 \$ 15.00 / 0$
DA signaling upon the morphological, functional, and behavioral correlates of alcohol withdrawal. In particular, by using an integrated strategy of investigation we assessed: aversive limbic memory as a distinctive form of emotional memory, spine density and morphology in NAc MSNs, immunoreactivity for both TH and PSD-95, long-term plasticity at the striatal postsynaptic component, DA levels in the NAc by in vivo microdialysis, and the putative recovery effect of acute L-3,4-dihydroxyphenylalanin (L-DOPA) treatment during withdrawal. The possibility that boosting DA signaling may lead to a rescue of alcohol-related dysfunction suggests therapeutic implications.

\section{Materials and Methods}

Animals

Male Sprague-Dawley rats (Charles River Laboratories), weighing 125$155 \mathrm{~g}$ at the beginning of treatment, were housed individually in single cages. No extra chow or water was supplied and animals were fed only with a liquid diet, continuously available, prepared as previously reported (Spiga et al., 2014). Briefly, fresh whole cow milk, 910-970 ml (CoaPla), vitamin A $5000 \mathrm{IU} / \mathrm{L}$, and sucrose $17 \mathrm{~g} / \mathrm{L}$ that supplies 1000.7 $\mathrm{kcal} / \mathrm{L}$, was freshly prepared daily. Temperature $22 \pm 2^{\circ} \mathrm{C}$ and humidity $60-65 \%$ were maintained under controlled environmental conditions (on a reverse $12 \mathrm{~h} \mathrm{light/dark} \mathrm{cycle).} \mathrm{Animals} \mathrm{were} \mathrm{divided} \mathrm{in} \mathrm{different}$ experimental groups: alcohol-naive controls (CTRL; continuously fed with alcohol-free milk), chronically alcohol-treated rats (EtOH-CHR; continuously fed with alcohol-containing milk and tested immediately after treatment was terminated), alcohol withdrawn rats (EtOH-WDL; continuously fed with alcohol-containing milk and tested $12 \mathrm{~h}$ after treatment was terminated), EtOH-WDL(48 h), and EtOH-WDL(14 d) rats tested, respectively, $48 \mathrm{~h}$ and $14 \mathrm{~d}$ following the interruption of the chronic alcohol diet. All experiments were conducted in accordance with the regulations of the Committee for the Protection and Use of Animals of the University of Palermo, Sassari and Cagliari, in accordance with current Italian legislation on animal experimentation (D.L. 26/2014) and the European directives (2010/63/EU) on care and use of laboratory animals (authorization no. 172/2017-PR to E.S.). Every effort was made to minimize the number of animals used and their sorrow.

\section{Experimental design}

Details of the experiments, groups, factors, and analyses used are displayed in Table 1.

\section{Alcohol dependence induction}

Alcohol dependence was induced by feeding rats with a liquid diet as previously reported (Spiga et al., 2014). Briefly, the mix was presented at the same time of the day (09:30 A.M.). The diet was gradually enriched with $2.4 \%$ (Days $1-4$ ), $4.8 \%$ (Days 5-8), and 7.2\% (Days 9-20) alcohol and administered for $20 \mathrm{~d}$. The animal body weight, as well as alcohol and liquid intake, were monitored daily. Under these experimental conditions blood alcohol concentrations reach $76.41 \pm 16.41 \mathrm{mg} / \mathrm{dl}$ within 30 min of liquid diet suspension; and $<1 \mathrm{mg} / \mathrm{dl}$ at $12 \mathrm{~h}$ after liquid diet suspension (EtOH-WDL rats; Spiga et al., 2014).

Controls (CTRL) were pair-fed with alcohol-free milk liquid diet.

Withdrawal signs, including body tremors, tail stiffness, and irritability to touch (vocalization) were monitored and scored by a skilled experimenter blind to treatments using a rating scale as follows: $0=$ no sign, $1=$ moderate, 2 = severe (Spiga et al., 2014). Individual withdrawal sign rating was then combined to produce a global score of withdrawal severity with a maximum total of 6 .

\section{Emotional-object recognition test}

Apparatus. The Emotional-object recognition (EOR) test was used for the assessment of aversive limbic memory. It used two distinct contexts (A and B) placed in different rooms. Context "A chamber" is a rectangular arena with white floors (100 long $\times 30$ wide $\times 43$ high, cm). Rat behavior was recorded and analyzed by ANY MAZE Video Tracking System (Ugo Basile). A left and a right zone $(40 \times 30 \mathrm{~cm})$ on both ends of Context A chamber, as well as a neutral zone in the center of the box (20 $\mathrm{cm}$ ) represented the arena settings (modified from Ramirez et al., 2015). 
Table 1. Experimental design

\begin{tabular}{|c|c|c|c|}
\hline Experiments & & Groups & Analysis \\
\hline \multirow[t]{4}{*}{ Behavior } & Signs of withdrawal & $\begin{array}{l}\text { CTRL; EtOH-WDL; CTRL + --DOPA; } \\
\text { EtOH-WDL + L-DOPA }\end{array}$ & $\begin{array}{l}\text { Kruskal-Wallis test, Dunn's post hoc test; } \\
\text { factor: withdrawal Mann-Whitney } U \text { test; factor: L-DOPA treatment }\end{array}$ \\
\hline & Locomotor activity & CTRL; EtOH-CRH; EtOH-WDL & Kruskal-Wallis test; factor: treatment \\
\hline & $\begin{array}{l}\text { Emotional-object recognition } \\
\text { test }\end{array}$ & $\begin{array}{l}\text { CTRL; EtOH-CRH; EtOH-WDL; CTRL + } \\
\text { L-DOPA; EtOH-WDL + L-DOPA }\end{array}$ & $\begin{array}{l}\text { one-way ANOVA, Bonferroni post hoc test; factor: treatment; two-way ANOVA, } \\
\text { Bonferroni post hoc test; factors: withdrawal; I-DOPA treatment }\end{array}$ \\
\hline & Tail-flick test & CTRL; EtOH-CRH; EtOH-WDL & one-way ANOVA; factor: treatment \\
\hline \multirow[t]{2}{*}{ Golgi-Cox, immunofluorescence } & TH; PSD-95 & $\begin{array}{l}\text { CTRL; EtOH-WDL; CTRL + L-DOPA; } \\
\text { EtOH-WDL + L-DOPA }\end{array}$ & two-way ANOVA, Bonferroni post hoc test; factors: withdrawal; L-DOPA treatment \\
\hline & $\begin{array}{l}\text { Spine analysis (stubby, } \\
\text { mushroom, long thin, filopodia) }\end{array}$ & $\begin{array}{l}\text { CTRL; EtOH-WDL; CTRL + L-DOPA; } \\
\text { EtOH-WDL + L-DOPA }\end{array}$ & two-way ANOVA, Bonferroni post hoc test; factors: withdrawal; L-DOPA treatment \\
\hline \multirow[t]{2}{*}{$\begin{array}{l}\text { Electrophysiology, AMPA/NMDA } \\
\text { ratio; LTD }\end{array}$} & in vivo, $\mathrm{L}-\mathrm{DOPA}$ & $\begin{array}{l}\text { CTRL; EtOH-CRH; EtOH-WDL CTRL + } \\
\text { L-DOPA; EtOH-WDL + L-DOPA }\end{array}$ & $\begin{array}{l}\text { one-way ANOVA, Bonferroni post hoc test; factor: treatment two-way ANOVA, } \\
\text { Bonferroni post hoc test; factors: withdrawal; L-DOPA treatment }\end{array}$ \\
\hline & in vitro, $\mathrm{DA}$ & $\begin{array}{l}\text { CTRL; EtOH-WDL; EtOH-WDL + DA; } \\
\text { EtOH-WDL + DA + SCH; } \\
\text { EtOH-WDL + DA + Sulp }\end{array}$ & one-way ANOVA, Bonferroni post hoc; factor: treatment \\
\hline Microdialysis & in vivo & $\begin{array}{l}\text { CTRL; EtOH-WDL CTRL + L-DOPA; } \\
\text { EtOH-WDL + L-DOPA }\end{array}$ & two-way ANOVA, Sidak/Tuckey post hoc test; factors: withdrawal; time \\
\hline
\end{tabular}

SCH, SCH23390; Sulp, sulpiride.

a

$\sum$ Habituation $\sum_{1 \mathrm{~h}} \sum_{\text {CONTEXT B }}^{\begin{array}{c}\text { Cued Fear-conditioned } \\ \text { Learning }\end{array}}$
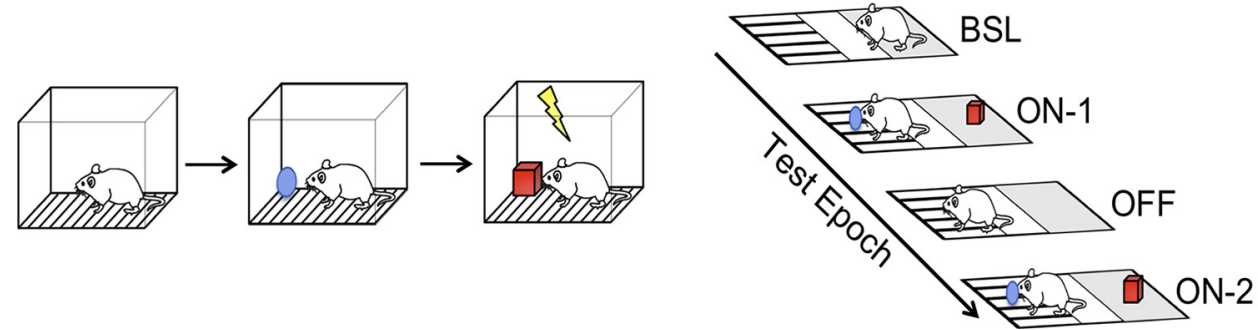

b

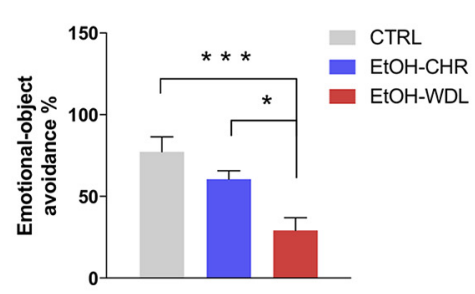

C

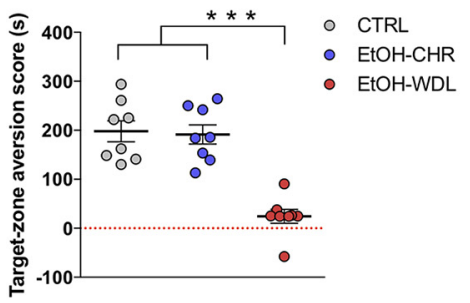

d

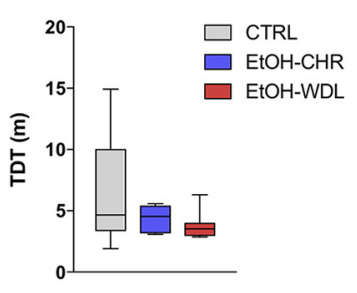

e

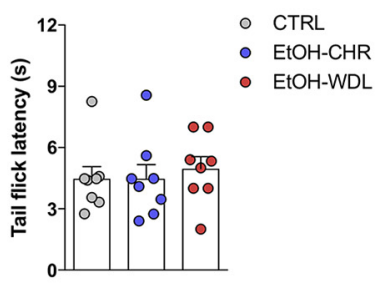

Figure 1. Alcohol withdrawal disrupts limbic memory formation. Limbic memory was assessed in rats by $(\boldsymbol{a})$ the EOR test, here schematically represented. Four hours after the cued fearconditioned learning, rats were put into the central zone of Context A chamber and tested for individual zone preference in epoch BSL. Afterward emotional-object avoidance and target-zone aversion were assessed in epoch $0 \mathrm{~N}-1$ (objects in the arena), $0 \mathrm{FF}$ (objects removed from the arena), $0 \mathrm{~N}-2$ (objects in the arena). Twelve hour alcohol-withdrawn rats (EtOH-WDL) displayed reduced (b) emotional object avoidance and (c) target-zone aversion with respect to alcohol-naive control (CTRL) and chronically-EtOH-exposed (EtOH-CHR) rats. No significant differences between CTRL and EtOH-CHR were recorded. EtOH-WDL did not show sensory-motor impairment, in terms of (d) TDT when video-tracked during the BSL epoch in context A chamber, and (e) tail-flick latency following the EOR test. Each bar represents the mean $\pm \mathrm{SEM} ; n=8$ rats. Each box-and-whisker plot represents the median (horizontal line in the box), $25-75 \%$ (box), and min-to-max (whiskers) values of $n=8$ rats. ${ }^{* *} p<0.001,{ }^{*} p<0.05$.

Context A chamber was customized with two different, nontoxic objects (i.e., a plastic ball, $3.5 \mathrm{~cm}$ diameter, and a plastic pepper, $3 \times 3 \times 4 \mathrm{~cm}$ ) that were placed against the end walls of the left and the right zones of the arena, according to the procedure described below. Objects and their position were counter-balanced within the experimental groups.

Context "B chamber" was a rectangular chamber $(45 \times 22 \times 22 \mathrm{~cm})$, and equipped with grid floor, opaque ceilings, and dark walls. Rats were allowed to explore Context B chamber for habituation and conditioned/ cued-learning; they were then tested in Context A chamber for emotional recognition. Floors and walls of the chambers were thoroughly cleaned with $70 \%$ isopropanol, then dried with tissue paper, and rinsed again with water 10 min before animals' entry into the chambers. Rats were transported to and from the experimental room in their home cages using a wheeled cart. The cart and cages remained in an anteroom to the experimental rooms during all behavioral experiments (Fig. 1a).

Habituation. Habituation took place in Context B chamber and consisted of two separate sessions: environmental exploration, during which rats were put in the arena and left undisturbed to explore the chamber for 5 min; neutral-object exploration, in which an object (plastic ball or pepper) was placed in the opposite corner with respect to the rat's entry and presented to the animals for $10 \mathrm{~min}$. Between the two sessions, rats were taken and returned to their home cages for $10 \mathrm{~min}$.

Cued fear-conditioned learning. One hour after neutral-object exploration, rats were replaced in Context B chamber, presented with a novel 
object (emotional-object)and trained for fear conditioning. The session was $560 \mathrm{~s}$ in duration, and five $2 \mathrm{~s}, 0.3 \mathrm{~mA}$ shocks were delivered at 120 , $200,280,360,440$, and $520 \mathrm{~s}$. At the end of the session, animals returned in their home cages for $4 \mathrm{~h}$ retention interval.

Emotional-object recognition: Context A chamber. Four hours after cued-fear conditioned learning, animals were put into Context A chamber and tested for emotional-object discrimination and object-place aversion in a neutral context, A chamber. They were allowed to freely explore the new context for $5 \mathrm{~min}$; for each rat, favorite zone, between left and right ones, was recorded at epoch baseline (BSL). Afterward, the object experienced during fear conditioning (emotional-object) was placed in the favorite zone; the object experienced during habituation (neutral-object) was placed in the less preferred zone. Rats explored objects and zones from minutes 5 to 8 (epoch $\mathrm{ON}-1$ ). During minutes $8-11$, objects were removed from the arena (epoch OFF). During minutes 11-14, the objects were reintroduced in the same positions as minutes 5-8 (epoch ON-2). Finally, rats were placed in their home cages and carted back to the holding room. At the end of each experimental session, both objects and arena were cleaned with a 70\% solution of isopropanol. Time spent on exploring objects and zones was recorded along the epochs. Emotional-object discrimination was measured by "emotionalobject avoidance \%", which was calculated as follows: $100-[$ (time spent on the emotional-object/time spent on neutral- + emotional-object) $\%)]$. Object-place conditioning was measured by "target-zone aversion score", which was calculated as the difference between time spent on the target zone during BSL and the mean time spent on the target zone during $\mathrm{ON}$ epochs.

Drugs (behavior). L-DOPA was used at the dose of $6 \mathrm{mg} / \mathrm{kg}$ (Nikolaus et al., 2016) in all the experimental procedures; the dose of $1.5 \mathrm{mg} / \mathrm{kg}$ was also tested in the aversive limbic-memory experiment. L-DOPA was administered by a subcutaneous single injection $1 \mathrm{~h}$ before the cued fearconditioned learning session. In addition, to prevent the peripheral decarboxylation of DOPA, the DOPA decarboxylase inhibitor benserazide $(6 \mathrm{mg} / \mathrm{kg})$ was coinjected. Control rats received the same volume of vehicle $(1 \mathrm{ml} / \mathrm{kg})$, at the same time schedule.

\section{Locomotor activity}

Locomotor activity was measured in the Context A chamber during the 5 min epoch BSL of the emotional object recognition experiment. The motor pattern of the rats was recorded by using an automatic videotracking system (ANY MAZE, Ugo Basile), and measured as total distance traveled (TDT; in meters).

\section{Hot-water immersion, tail-flick test}

Nociception was explored by measuring tail-flick latencies in the "hotwater immersion, tail flick" test following the emotional object recognition test. Rats' tails were immersed for $2 \mathrm{~cm}$ in a water bath apparatus (Instruments Srl) maintained at $52 \pm 0.5^{\circ} \mathrm{C}$. Latency to response was determined by a vigorous tail flick by a skilled experimenter blind to treatments. A cutoff time of $10 \mathrm{~s}$ was imposed to minimize tissue damage.

\section{Golgi-Cox and simultaneous immunofluorescence}

Rats were deeply anesthetized with chloral hydrate and perfused intracardially with $0.9 \%$ saline solution $(400 \mathrm{ml})$ followed by $4 \%$ paraformaldehyde, pH $7.4(200 \mathrm{ml})$. The removed brains were postfixed in same fixative overnight at $4 \mathrm{C}^{\circ}$. Afterward brains were washed in $0.4 \mathrm{M}$ Sorenson's phosphate buffer (PBS) for $8 \mathrm{~h}$ ( 8 changes of $1 \mathrm{~h}$ each) and placed in $20 \mathrm{ml}$ of Golgi-Cox solution for 2 weeks. Brains were cut in $50-\mu \mathrm{m}$-thick coronal slices using a vibratome Leica VT 1000S. Slices were developed in ammonia solution at $15 \%$ for $30 \mathrm{~min}$ (Spiga et al., 2014), washed, and collected in PBS for the following free-floating immunostaining. To prevent nonspecific binding, slices were preincubated in 10\% normal goat serum solution containing $5 \%$ bovine serum albumin and $1 \%$ Triton $\mathrm{X}-100$ in PBS overnight at $4^{\circ} \mathrm{C}$. At this point, sections were incubated with two primary antibodies: polyclonal rabbit anti-TH (1:200; Santa Cruz Biotechnology) and mouse anti-PSD-95 (1:200; Santa Cruz Biotechnology) in PBS for $48 \mathrm{~h}$ at $4^{\circ} \mathrm{C}$.

Sections were washed $3 \times 10 \mathrm{~min}$ in PBS, and incubated in biotinylated goat anti-mouse (1:200; Vector Laboratories), and anti-rabbit AlexaFluor 594 (1:200; Invitrogen) in PBS for $4 \mathrm{~h}$ at RT. After this step, slices were incubated in fluorescein-streptavidin (1:200; Vector Laboratories) in PBS for $1 \mathrm{~h}$ at RT and then washed $3 \times 10 \mathrm{~min}$ in PBS and coverslipped with VECTASHIELD (Vector Laboratories).

\section{TH and PSD-95 counts}

For counts, confocal images were obtained $24 \mathrm{~h}$ after the conclusion of the histology procedure. The TH and PSD-95 volume were determined as follows:

For each dataset ( $n=6-8$ rats per group), four surfaces $(x=40 \mu \mathrm{m}$; $y=40 \mu \mathrm{m} ; z=10$; ROI) were randomly chosen by an experimenter blind to treatments. In each ROI, by a simple thresholding, objects were created and their volume was calculated, summed and expressed as volume $/ \mu \mathrm{m}^{3}$.

\section{Spines density and classification}

For spines density evaluation, $n=40$ distal dendritic segments (at least $20 \mu \mathrm{m}$ long), from confocal images of shell MSN of each experimental group ( $n=6-8$ rats per group), were collected and automatically (filament tool Bitplane Imaris 7.4) counted. Using the same dendritic segment, we classified spine typology according to Spiga et al. (2014).

\section{Laser scanning confocal microscopy}

Confocal analysis was performed using a Leica 4D confocal laserscanning microscope with an argon-krypton laser. Confocal images were generated using $100 \times$ oil (N.A. 1.3). Each frame was acquired eight times and then averaged to obtain noise-free images. Scans were performed in sequence using channels for fluorescein, rhodamine and reflection, using, exactly, the same range in $z$-axis. Resulting datasets were combined, frame by frame, for simultaneous rendering.

\section{Rendering}

Maximum intensity and extended focus algorithms were used for surface rendering to display and analyze the anatomical structures. The rendered $3 \mathrm{D}$ surfaces were analyzed for counts and to show the interaction between fluorescence and Golgi-Cox stained elements. Colocalization analysis (Imaris 7.0) was also used.

\section{Electrophysiology experiments}

Coronal brain slices containing the NAc shell region were prepared as previously described (Spiga et al., 2014). Briefly, animals were subjected to deep anesthesia with isoflurane $2-5 \%$ and decapitated. Their brain was rapidly removed from the skull and transferred to a modified artificial CSF (ACSF) containing the following (in $\mathrm{mM}$ ): 220 sucrose, $2 \mathrm{KCl}, 0.2$ $\mathrm{CaCl}_{2}, 6 \mathrm{MgSO}_{4} 26 \mathrm{NaHCO}_{3}, 1.3 \mathrm{NaH}_{2} \mathrm{PO}_{4}$, and 10 D-glucose ( $\mathrm{pH} 7.4$, set by aeration with $95 \% \mathrm{O}_{2}$ and $5 \% \mathrm{CO}_{2}$ ). Coronal brain slices (thickness, $260 \mu \mathrm{m}$ ) containing the NAc shell were cut in ice-cold modified ACSF using a Leica VT1200S vibratome. Slices were then transferred immediately to a nylon net submerged in standard ACSF containing the following (in mM): $126 \mathrm{NaCl}, 3 \mathrm{KCl}, 2 \mathrm{CaCl}_{2}, 1 \mathrm{MgCl}_{2}, 26 \mathrm{NaHCO}_{3}, 1.25$ $\mathrm{NaH}_{2} \mathrm{PO}_{4}$, and 10 D-glucose ( $\mathrm{pH} 7.4$, set by aeration with $95 \% \mathrm{O}_{2} / 5 \%$ $\mathrm{CO}_{2}$ ) for at least $40 \mathrm{~min}$ at a controlled temperature of $35^{\circ} \mathrm{C}$. After subsequent incubation for at least $1 \mathrm{~h}$ at room temperature, hemi-slices were transferred to the recording chamber, and continuously perfused with standard ACSF at a constant flow rate of $\sim 2 \mathrm{ml} / \mathrm{min}$. For all recordings, the temperature of the bath was maintained at $33^{\circ} \mathrm{C}$. Glutamatergic EPSCs were recorded, in the presence of the GABAA receptor antagonist bicuculline $(20 \mu \mathrm{M})$, with an AxoPatch 200-B amplifier, filtered at $2 \mathrm{kHz}$, and digitized at $5 \mathrm{kHz}$. For evoked EPSCs a bipolar concentric stimulating electrode was placed at the bottom of the NAc shell while recorded MSNs were always located $\sim 400 \mu \mathrm{m}$ above the stimulating electrode tip. For calculating the NMDA/AMPA ratio, AMPAr-mediated eEPSCs were recorded at a holding potential of $-65 \mathrm{mV}$, whereas NMDAr-mediated responses were recorded at a holding potential of $+40 \mathrm{mV}$ in the presence of the AMPA/kainate receptor antagonist CNQX $(5 \mu \mathrm{M})$. For LTD experiments, eEPSCs were recorded in voltage-clamped $(-65 \mathrm{mV})$ MSNs at a frequency of $0.05 \mathrm{~Hz}$ (baseline) for at least $10 \mathrm{~min}$; no differences were found in baseline currents at the stimulation used to evoke the $30 \%$ of maximal response; a low-frequency stimulation (LFS; 500 stimuli at $1 \mathrm{~Hz}$ ) paired with membrane depolarization (holding potential, $-50 \mathrm{mV}$ ) was then applied, and eEPSCs were then recorded 
Table 2. Rating of behavioral signs of withdrawal

\begin{tabular}{|c|c|c|c|c|c|c|c|c|c|c|c|}
\hline & \multicolumn{2}{|l|}{ CTRL } & \multicolumn{3}{|c|}{ EtOH-WDL $12 \mathrm{~h}$} & \multicolumn{3}{|c|}{ EtOH-WDL $48 \mathrm{~h}$} & \multicolumn{3}{|c|}{ EtOH-WDL $14 \mathrm{~d}$} \\
\hline & Median & IQR & Median & IQR & $p$ & Median & IQR & $p$ & Median & IQR & $p$ \\
\hline \multicolumn{12}{|l|}{ Global rating } \\
\hline Vehicle & 0.0 & $0.0-0.0$ & 3.0 & $3.0-4.5$ & $* * *$ & 2.0 & $1.0-2.0$ & $*$ & 0.0 & $0.0-0.5$ & n.s. \\
\hline L-DOPA & 0.0 & $0.0-0.0$ & 2.0 & $1.0-2.0$ & $\wedge \wedge$ & 1.0 & $0.5-1.0$ & n.s. & 0.0 & $0.0-0.5$ & n.s. \\
\hline \multicolumn{12}{|c|}{ Individual signs } \\
\hline \multicolumn{12}{|c|}{ Body tremors } \\
\hline Vehicle & 0.0 & $0.0-0.0$ & 0.5 & $0.0-1.0$ & $*$ & 0.0 & $0.0-0.5$ & n.s. & 0.0 & $0.0-0.0$ & n.s. \\
\hline L-DOPA & 0.0 & $0.0-0.0$ & 0.0 & $0.0-1.0$ & n.s. & 0.0 & $0.0-0.0$ & n.s. & 0.0 & $0.0-0.0$ & n.s. \\
\hline \multicolumn{12}{|c|}{ Tail stiffness } \\
\hline Vehicle & 0.0 & $0.0-0.0$ & 1.0 & $1.0-2.0$ & $* *$ & 1.0 & $0.5-2.0$ & $* *$ & 0.0 & $0.0-0.0$ & n.s. \\
\hline L-DOPA & 0.0 & $0.0-0.0$ & 0.5 & $0.0-1.0$ & n.s. & 0.0 & $0.0-0.0$ & n.s. & 0.0 & $0.0-0.0$ & n.s. \\
\hline \multicolumn{12}{|c|}{ Irritability to touch } \\
\hline Vehicle & 0.0 & $0.0-0.0$ & 2.0 & $1.0-2.0$ & $* * *$ & 0.5 & $0.0-0.5$ & n.s. & 0.0 & $0.0-0.5$ & n.s. \\
\hline L-DOPA & 0.0 & $0.0-0.0$ & 1.0 & $0.5-1.0$ & $\wedge$ & 1.0 & $0.0-1.0$ & n.s. & 0.0 & $0.0-0.5$ & n.s. \\
\hline
\end{tabular}

Each individual sign of withdrawal was rated on a $0-2$ point scale, with 0 representing absence of sign, 1 representing moderate severity, and 2 representing extreme severity. Individual withdrawal sign ratings were then combined to produce a global score. Data are indicated as median and interquartile range (IQR) of $n=8$ rats. ${ }^{* * *} p<0.001,{ }^{* *} p<0.01,{ }^{*} p<0.05$ Dunn's post hoc test versus CTRL; ${ }^{\wedge} p<0.01,{ }^{\wedge} p<0.05$ two-tailed Mann-Whitney $U$ test versus vehicle.

for the following $60 \mathrm{~min}$ at a frequency stimulation of $0.05 \mathrm{~Hz}$. LTD was calculated by averaging the EPSC amplitude values measured 50-60 min after LFS and expressed as percentage of baseline as average of the last $10 \mathrm{~min}$ of recording.

Drugs (electrophysiology). L-3,4-dihydroxyphenylalanin (L-DOPA; 6 $\mathrm{mg} / \mathrm{kg}$ ) was administered acutely by a subcutaneous injection $1 \mathrm{~h}$ before kill, in association with the peripheral antagonist of DOPA decarboxylase, benserazide $(6 \mathrm{mg} / \mathrm{kg})$. Moreover, the following drugs were tested in vitro by bath perfusion of NAc slices, obtained from the different experimental groups, for 5 min before applying LFS: dopamine $(10 \mu \mathrm{M})$, the D1R antagonist SCH23390 (10 $\mu \mathrm{M})$, and the D2R antagonist sulpiride $(10 \mu \mathrm{M})$.

\section{In vivo microdialysis studies}

Rats were anesthetized with Equitesin $(3 \mathrm{ml} / \mathrm{kg}$, i.p.) and placed in a stereotaxic apparatus. The skull was exposed, and a small hole was drilled on one side. The probe was implanted vertically in the NAc shell $(\mathrm{A}+2.2$; $\mathrm{L}+1.0$ from bregma; V-7.8 from dura) according to Paxinos and Watson (1998), and then fixed on the skull with dental cement. Rats were housed in transparent plastic (Plexiglas) hemispheric bowls with liquid diet available. Experiments were performed on freely moving rats $24 \mathrm{~h}$ after probe implantation. A Ringer's solution (in mM: $147 \mathrm{NaCl}, 2.2$ $\mathrm{CaCl}_{2}, 4 \mathrm{KCl}$ ) was pumped through the dialysis probe at a constant rate of $1 \mu \mathrm{l} / \mathrm{min}$. Dialysate samples $(20 \mu \mathrm{l})$ were taken every $20 \mathrm{~min}$ and injected without purification into an HPLC apparatus equipped with a reversephase column (C8 $3.5 \mu \mathrm{m}$, Waters) and a coulometric detector (ESA Coulochem II) to quantify DA. The first electrode of the detector was set at $+130 \mathrm{mV}$ (oxidation) and the second at $-175 \mathrm{mV}$ (reduction). The composition of the mobile phase was $50 \mathrm{~mm} \mathrm{NaH}{ }_{2} \mathrm{PO}_{4}, 0.1 \mathrm{~mm} \mathrm{Na}_{2}$ EDTA, $0.5 \mathrm{~mm} N$-octyl sodium sulfate, and $15 \%(\mathrm{v} / \mathrm{v})$ methanol, pH 5.5. The sensitivity of the assay for DA was $5 \mathrm{fmol} / \mathrm{sample}$. At the end of the experiment, animals were killed and their brains were removed and stored in formalin $(8 \%)$ before histological analysis. To this end, brains were cut on a vibratome in serial coronal slices $(20 \mu \mathrm{m})$ oriented according to Paxinos and Watson (1998) to locate the placement of the microdialysis probe.

\section{Statistical analysis}

All data are expressed as the mean \pm SEM unless differently indicated. All data were tested for normality and equal variances. When data exhibit normality and equal variances, differences between groups were determined using either a one- or two-way ANOVA followed by Bonferroni post hoc test when the main effect was significant $(p<0.05)$. Data from in vivo microdialysis were analyzed by using repeated-measures (RM) twoway ANOVA, followed by post hoc Sidak or Tukey tests, when necessary. Data that did not display equal variances and data from the withdrawal rating scale were analyzed by Kruskal-Wallis, followed by Dunn's post hoc test when necessary and Mann-Whitney $U$ nonparametric tests.

Statistical analysis was performed using Prism 6.0 (GraphPad Soft- ware). No statistical methods were used to predetermine sample sizes but our sample sizes are similar to those reported in previous publications. Grubbs outlier test was performed on immunofluorescence images that varied $>2$ SD from the mean were removed and not considered for data analysis ( 1 of 8 images for 2 of 6 samples in CTRL group; 1 of 8 images for 2 of 8 samples in EtOH-WDL and EtOH-WDL + L-DOPA groups).

\section{Results}

Signs of withdrawal from ethanol liquid diet administration The signs of withdrawal at $12 \mathrm{~h}, 48 \mathrm{~h}$, and $14 \mathrm{~d}$ after EtOH diet suspension were scored immediately before the EOR testing in the different experimental groups. Each individual sign of withdrawal was rated on a $0-2$ point scale; then they were combined to produce a global score of withdrawal severity with a maximum total of 6 (Table 2). Data analysis on global score rating, including withdrawal as main factor, revealed significant differences among the groups (Kruskal-Wallis statistic $=27.84, p<0.001$ ). In particular, withdrawal global score was significantly higher in rats at $12 \mathrm{~h}$ withdrawal from EtOH liquid diet than controls $(p<0.001$, Dunn's multiple-comparisons test) and $48 \mathrm{~h}(p=0.0224$, Dunn's multiple-comparisons test) time points, whereas no differences were observed at $14 \mathrm{~d}(p>0.999$, Dunn's multiplecomparisons test). The analysis of individual signs of withdrawal indicated significant differences in body tremor (Kruskal-Wallis statistic $=9.874, p=0.0197)$, which was significantly higher in EtOH-WDL (12 h) than CTRLs ( $p=0.0201$, Dunn's multiplecomparisons test); tail stiffness (Kruskal-Wallis statistic $=20.0$, $p=0.0002$ ), which was significantly higher in EtOH-WDL (12 h; $p=0.0025$, Dunn's multiple-comparisons test) and EtOH-WDL (48 h) rats ( $p=0.0094$, Dunn's multiple-comparisons test) than CTRL rats; and irritability to touch (Kruskal-Wallis statistic = $19.95, p=0.0002)$, which was significantly higher in EtOH-WDL (12 h) than CTRLs ( $p=0.0001$, Dunn's multiple-comparisons test).

The administration of L-DOPA in EtOH-WDL rats significantly decreased withdrawal global score [two-tailed Mann-Whitney test, including L-DOPA treatment as factor: EtOH-WDL (12 h) + L-DOPA vs EtOH-WDL ( $12 \mathrm{~h}): U=5.0, p=0.0040]$ and irritability to touch [two-tailed Mann-Whitney test EtOH-WDL (12 h) + L-DOPA vs EtOH-WDL (12 h): $U=9.0, p=0.0131]$ compared with vehicle.

\section{Aversive limbic memory}

We explored the consequences of the abrupt abstinence from alcohol chronic exposure on learning and memory processes that 
a

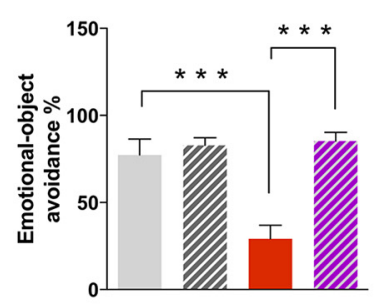

b

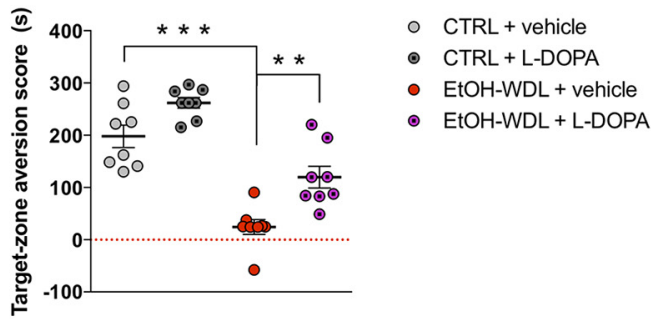

C

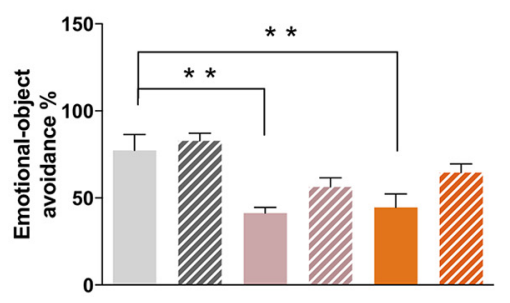

- CTRL + vehicle

UA CTRL + L-DOPA

EtOH-WDL $(48 \mathrm{~h})+$ vehicle

VA EtOH-WDL $(48 \mathrm{~h})+$ L-DOPA

EtOH-WDL $(14 \mathrm{~d})+$ vehicle

ys EtOH-WDL (14 d) + L-DOPA d

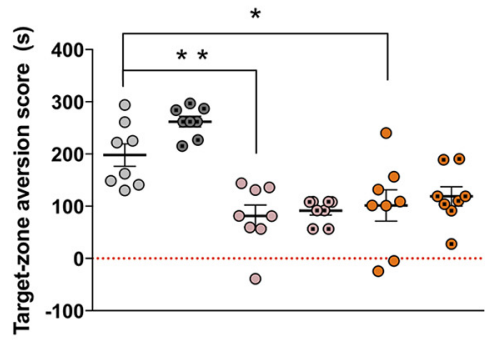

- $\mathrm{CTRL}+$ vehicle

- CTRL + L-DOPA

- EtOH-WDL (48 h) + vehicle

- EtOH-WDL $(48 \mathrm{~h})+\mathrm{L}-\mathrm{DOPA}$

- EtOH-WDL (14 d) + vehicle

- EtOH-WDL (14 d) + L-DOPA e

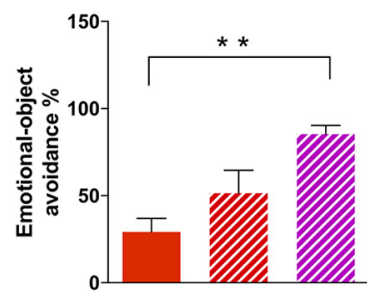

EtOH-WDL + vehicle

U/ EtOH-WDL + L-DOPA $1.5 \mathrm{mg} / \mathrm{kg}$

थ EtOH-WDL + L-DOPA $6.0 \mathrm{mg} / \mathrm{kg}$ f

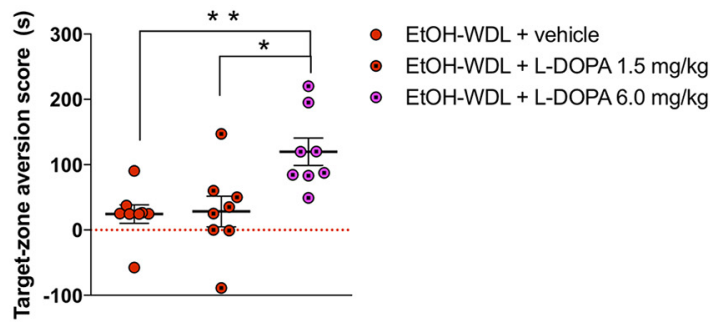

Figure 2. Limbic memory disruption was rescued by L-DOPA/benserazide ( $\mathrm{L}-\mathrm{DOPA}$ ) after $12 \mathrm{~h}$ withdrawal. Twelve hour alcohol-withdrawn rats administered with L-D0PA (EtOH-WDL $+\mathrm{L}-\mathrm{DOPA})$ displayed increased $(\boldsymbol{a})$ emotional object avoidance and $(\boldsymbol{b})$ target-zone aversion score with respect to $12 \mathrm{~h}$ alcohol-withdrawn rats receiving vehicle (EtOH-WDL + vehicle), up to alcohol-naive control (CTRL) rats' level. Limbic memory disruption was long lasting: alcohol-withdrawn rats showed decreased (c) emotional object avoidance and (d) target-zone aversion score following $48 \mathrm{~h}$ [EtOH-WDL (48 h)] and $14 \mathrm{~d}$ [EtOH-WDL (14 d)] of withdrawal. Long lasting limbic memory disruption in EtOH-withdrawn rats was not rescued by late stimulation of dopamine transmission. Preconditioning L-DOPA is not effective at significantly increasing (c) emotional object avoidance and (d) target-zone aversion score in EtOH-WDL (48 h) and EtOH-WDL (14 d) rats. In contrast, the rescuing effect of early ( $12 \mathrm{~h}$ withdrawal) L-DOPA administration was dose-dependent on both ( $\boldsymbol{e}$ ) emotional object avoidance and $(\boldsymbol{f})$ target-zone aversion score. Each bar represents the mean \pm SEM; $n=8$ rats. ${ }^{* * *} p<0.001 ;{ }^{* *} p<0.01 ;{ }^{*} p<0.05$.

occur when rats adapt their behavior on the basis of the association with an aversive experience.

To address this issue, we used a novel task that enables to study the formation of limbic memory as a result of the acquisition and retrieval of fear-conditioning-biased declarative memory traces by assessing rat discrimination of an emotionalobject and object-place aversion (Brancato et al., 2016; Fig. 1a). We found that whereas control- and chronically-EtOH exposed rats avoided the exploration of the fear-conditioned cue and displayed conditioned object-place aversion, early withdrawn rats from a chronic alcohol diet (EtOH-WDL) displayed disrupted acquisition of cue-paired aversive inputs such as decreased emotional object avoidance (one-way ANOVA, including treatment as main factor: $F_{(2,21)}=10.51, p=0.0007$; Bonferroni post hoc test: CTRL vs EtOHWDL $t=4.516, \mathrm{df}=21, p<0.001$; EtOH-CHR vs EtOH-WDL $t=$ 2.945, $\mathrm{df}=21, p<0.05$; Fig. $1 b)$ and decreased target-zone aversion (one-way ANOVA: $F_{(2,21)}=27.51, p<0.0001$; Bonferroni post hoc test: CTRL vs EtOH-WDL $t=6.542, \mathrm{df}=21, p<0.001$; EtOH-CHR vs EtOH-WDL $t=6.299, \mathrm{df}=21, p<0.001$; Fig. $1 c$ ) with respect to alcohol-naive control (CTRL) and chronically-EtOH-exposed (EtOH-CHR) rats, notwithstanding the absence of sensory/ motor impairment in terms of TDT when video-tracked during the BSL epoch in context A chamber (Kruskal-Wallis test, $p=0.2685$; Fig. $1 d$ ), and tail-flick latency following the EOR test (one-way ANOVA, $F_{(2,21)}=0.2070, p=0.8147$; Fig. $1 e$ ).

When L-DOPA $(6 \mathrm{mg} / \mathrm{kg}$, s.c., in association with benserazide $6 \mathrm{mg} / \mathrm{kg}$, s.c.) was administered $1 \mathrm{~h}$ before the fear conditioning paradigm at $12 \mathrm{~h}$ of abstinence, rats reversed their behavioral pattern and displayed acquisition and retrieval of the cue-fear association in a similar pattern as alcohol-naive controls. Indeed, EtOH-WDL + L-DOPA-treated rats displayed increased emotional object avoidance (two-way ANOVA, including withdrawal and L-DOPA treatment as factors, L-DOPA: $F_{(1,28)}=19.96, p=$ 0.0001; withdrawal: $F_{(1,28)}=10.97, p=0.0026$; interaction: $F_{(1,28)}=13.50, p=0.0010$; Bonferroni post hoc test: CTRL + vehicle vs EtOH-WDL + vehicle $t=4.94$, df $=28, p=0.0002$; EtOH-WDL + vehicle vs EtOH-WDL $+\mathrm{L}-\mathrm{DOPA} t=5.757, \mathrm{df}=$ $28, p<0.001$; Fig. $2 a$ ) and target-zone aversion score (two-way ANOVA considering withdrawal and L-DOPA treatment as factors, L-DOPA: $F_{(1,28)}=21.09, p<0.0001$; withdrawal: $F_{(1,28)}=$ 82.68, $p<0.0001$; Bonferroni post hoc test: CTRL+vehicle vs EtOH-WDL+vehicle $t=7.068$, df $=28, p<0.0001$; EtOH- 
a

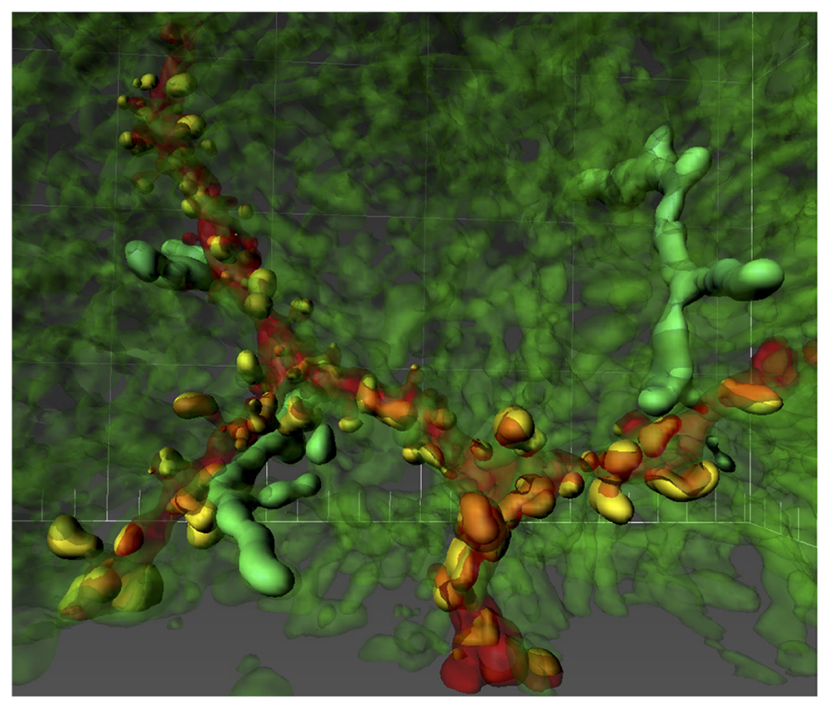

C

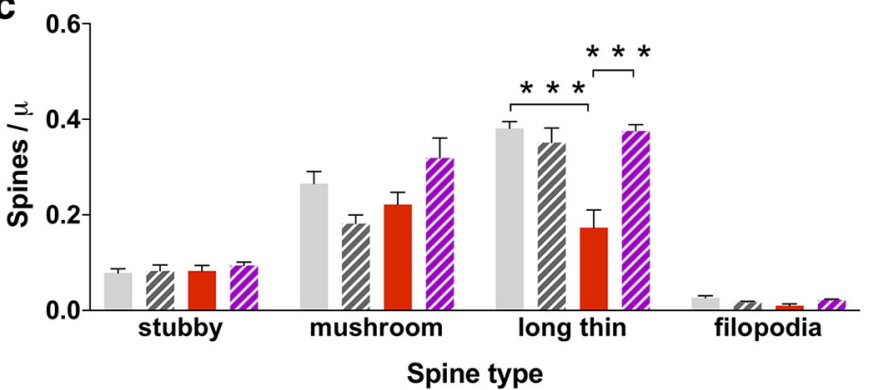

CTRL

थS CTRL + L-DOPA

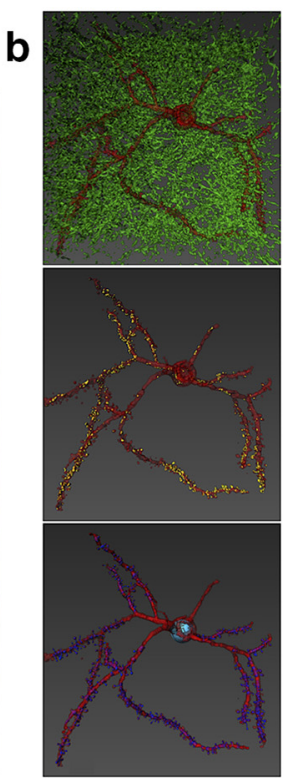

CTRL

d

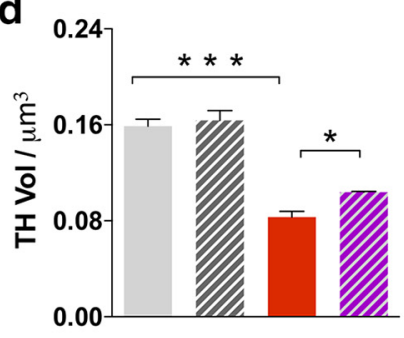

EtOH-WDL
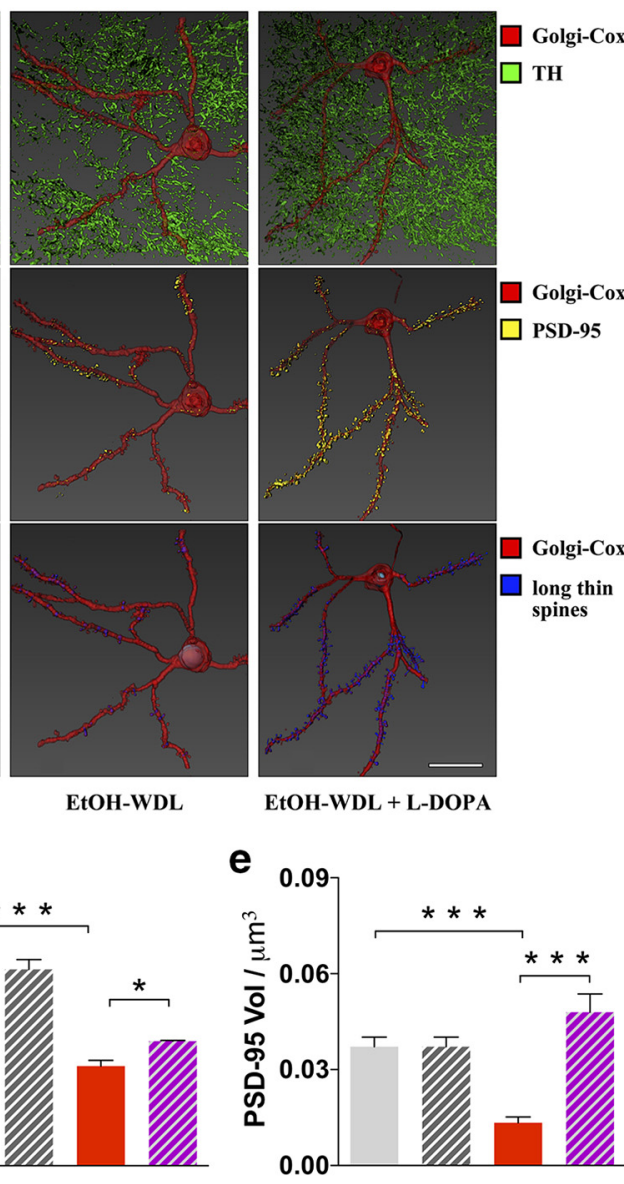

Figure 3. DA increase reverts aberrant structural plasticity in the NAc of alcohol-withdrawn rats. $\boldsymbol{a}$, Representative 3D reconstruction of the simultaneous visualization of Golgi-Cox stained MSNs. $\boldsymbol{b}, 3 \mathrm{D}$ reconstruction of the simultaneous visualization of Golgi-Cox stained MSNs (red), DA projections (TH+; green), PSD-95 (yellow), and long-thin spines (blue) in alcohol-naive control (CTRL), $12 \mathrm{~h}$ alcohol-withdrawn rats (EtOH-WDL), and $12 \mathrm{~h}$ alcohol-withdrawn rats administered with L-DOPA (EtOH-WDL + L-DOPA) Scale bar $20 \mu \mathrm{m}$. L-DOPA administration restores the aberrant structural plasticity of the synaptic triad in the NAc of withdrawn-rats. Indeed, L-DOPA (c) selectively expanded the density of long-thin spines to similar values as controls; $(\boldsymbol{d})$ increased TH levels and $(\boldsymbol{e})$ produced a complete restoring of the immunolabeling for PSD-95 in the NAc. Each bar represents the mean \pm SEM; $n=6-8$ rats. ${ }^{* *} p<0.001,{ }^{*} p<0.05$.

$\mathrm{WDL}+$ vehicle vs EtOH-WDL $+\mathrm{L}-\mathrm{DOPA} t=3.886, \mathrm{df}=28, p=$ 0.0034; Fig. 2b) up to CTRL level.

Interestingly, limbic memory disruption in EtOH-WDL rats was recorded in the EOR task after $48 \mathrm{~h}$ and $14 \mathrm{~d}$ of withdrawal, highlighting the rigid persistence of the disrupted processing of emotionally salient information. Indeed, at $48 \mathrm{~h}$ and $14 \mathrm{~d}$ of withdrawal, EtOH-WDL rats showed decreased emotional object avoidance [two-way ANOVA, including withdrawal and L-DOPA treatment as factors, L-DOPA: $F_{(1,42)}=7.188, p=0.0104$; withdrawal: $F_{(2,42)}=14.52, p<0.0001$; interaction: $F_{(2,42)}=0.7173$, $p=0.4940$; Bonferroni post hoc test: CTRL+vehicle vs EtOHWDL $(48 \mathrm{~h})+$ vehicle $t=4.129, \mathrm{df}=42, p=0.0025$; $\mathrm{CTRL}+$ vehicle vs EtOH-WDL(14 d) + vehicle $t=3.755, \mathrm{df}=42$, $p=0.0079$; Fig. $2 c$ ] and target-zone aversion score [two-way ANOVA including withdrawal and L-DOPA treatment as factors, L-DOPA: $F_{(1,42)}=3.6, p=0.0647$; withdrawal: $F_{(2,42)}=30.62$, $p<0.0001$; interaction: $F_{(2,42)}=1.106, p=0.3402$; Bonferroni post hoc test: CTRL+vehicle vs EtOH-WDL(48 h) +vehicle $t=$ $4.19, \mathrm{df}=42, p=0.0021 ; \mathrm{CTRL}+$ vehicle vs EtOH-WDL(14 d) + vehicle $t=3.472, \mathrm{df}=42, p=0.0181$; Fig. $2 d$ ], with respect to alcohol-naive controls (CTRL). L-DOPA administration did not exert the same rescuing effect on aversive limbic memory when it was administered at $48 \mathrm{~h}$ and $14 \mathrm{~d}$ of withdrawal [emotional-object avoidance, Bonferroni post hoc: EtOH$\mathrm{WDL}(48 \mathrm{~h})+$ vehicle vs EtOH-WDL$(48 \mathrm{~h})+\mathrm{L}-\mathrm{DOPA} t=1.725$, $\mathrm{df}=42, p>0.999$; EtOH-WDL $(14 \mathrm{~d})+$ vehicle vs EtOHWDL(14 d) +L-DOPA $t=2.292, \mathrm{df}=42, p=0.4044$; Fig. $3 a$; target-zone aversion score, Bonferroni post hoc: EtOH-WDL(48 h) + vehicle vs EtOH-WDL(48 h) $+\mathrm{L}-\mathrm{DOPA} t=0.3578, \mathrm{df}=42$, $p>0.999$; EtOH-WDL(14 d) + vehicle vs EtOH-WDL(14 d) + $\mathrm{L}_{-}$ DOPA $t=0.6285, \mathrm{df}=42, p>0.999$; Fig. $2 c, d]$.

In contrast, the rescuing effect of early ( $12 \mathrm{~h}$ withdrawal) L-DOPA administration was dose-dependent on both emotional object avoidance (one-way ANOVA, considering treatment as main factor: $F_{(2,21)}=9.275, p=0.0013$; Bonferroni post hoc test: EtOH-WDL+vehicle vs EtOH-WDL + L-DOPA $6.0 \mathrm{mg} / \mathrm{kg} t=$ 4.277, $\mathrm{df}=21, p<0.01$; Fig. $2 e$ ) and target-zone aversion score (one-way ANOVA considering treatment as main factor: $F_{(2,21)}=7.34, p=0.0038$; Bonferroni post hoc test: EtOH$\mathrm{WDL}+$ vehicle vs EtOH-WDL + L -DOPA $6.0 \mathrm{mg} / \mathrm{kg} t=3.386$, $\mathrm{df}=21, p<0.01 ;$ EtOH-WDL + L -DOPA $1.5 \mathrm{mg} / \mathrm{kg}$ vs EtOH- 
a

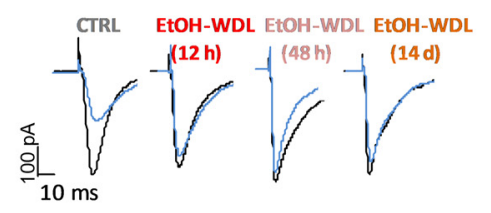

b

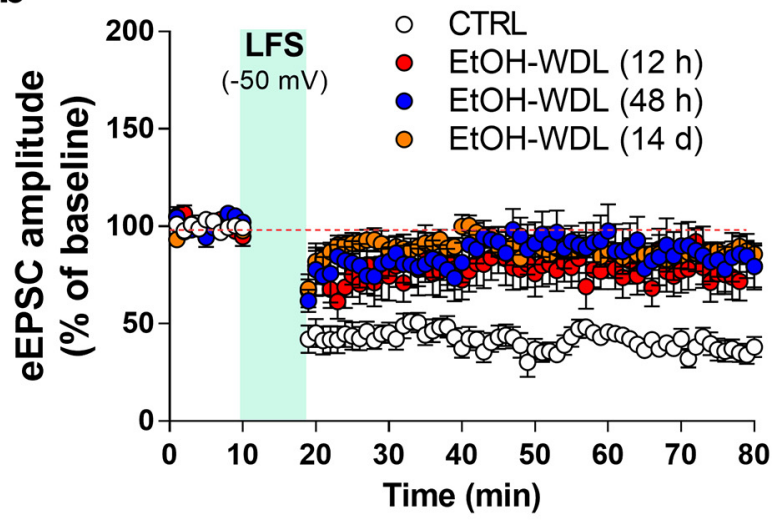

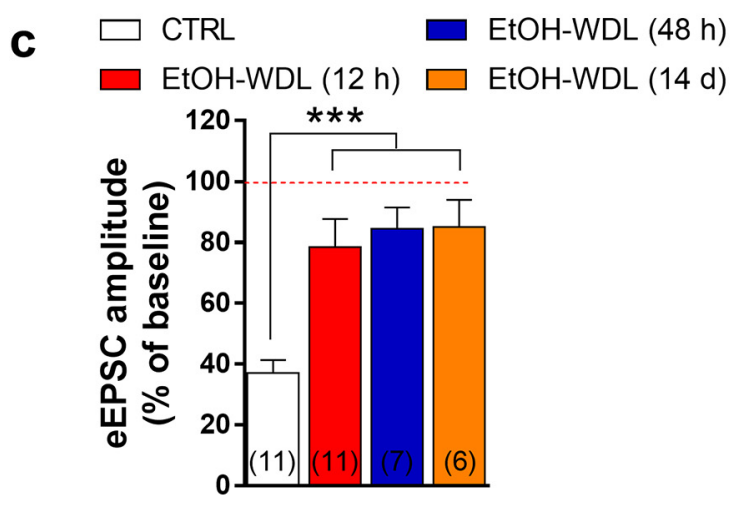

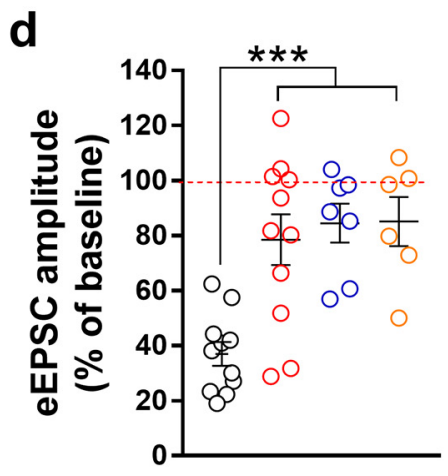

Figure 4. Effects of EtOH withdrawal on LTD formation in rat NAC MSNs. AMPAR-mediated eEPSCs were recorded in single voltage-clamped (-65 mV) MSNs of the NAc shell obtained from the different groups of animals [ $n$ of animals: CTRL $=5$; EtOH-WDL $(12 \mathrm{~h})=5$; EtOH-WDL $(48 \mathrm{~h})=4$; EtOH-WDL $(14 \mathrm{~d})=3]$. $\boldsymbol{a}$, Representative eEPSCs recorded before (black trace) and $60 \mathrm{~min}$ after (blue trace) LFS paired with depolarization $(-50 \mathrm{mV})$. $\boldsymbol{b}$, Scatter plot graph of the changes in eEPSC amplitude in CTRL and EtOH-WDL (12 h, $48 \mathrm{~h}$, and $14 \mathrm{~d}$ ) with data expressed as percentage of baseline. c, The graph illustrates the degree of LTD, calculated by averaging the eEPSC amplitude values measured $50-60$ min after LFS and expressed as percentage of baseline. The number of cells analyzed is indicated for each group. ${ }^{* *} p=0.0004$. $\boldsymbol{d}$, The scatter graph illustrates the distribution of individual values, averaged in $\boldsymbol{c}$. Color code is the same as in $c .{ }^{* *} p=0.0006$.

$\mathrm{WDL}+\mathrm{L}$-DOPA $6.0 \mathrm{mg} / \mathrm{kg} t=3.246, \mathrm{df}=21, p<0.05$; Fig. $2 f$ ). The dose of $1.5 \mathrm{mg} / \mathrm{kg}$ was discarded for further testing.

\section{Structural architecture of MSN dendritic spines}

Data of confocal microscopy on Golgi-Cox stained MSNs of the NAc shell (Fig. $3 a-e$ ) highlighted that early EtOH withdrawal produced a selective and significant reduction $(-49.89 \pm 5.15$ vs CTRL) in the density of long-thin spines compared with CTRL rats (two-way ANOVA including withdrawal and L-DOPA treatment as factors: effect of withdrawal $F_{(1,23)}=12.7, p=0.0016$; Bonferroni post hoc test $t=5.637, \mathrm{df}=23, p<0.001$; Fig. $3 b, c$ ). Subsequent immunostaining for both TH and PSD-95 measured in NAc shell slices from $12 \mathrm{~h}$ withdrawn rats, revealed a significant reduction in the immunoreactivity for both TH (44.34 \pm 3.2\%; two-way ANOVA including withdrawal and L-DOPA treatment as factors: effect of withdrawal $F_{(1,23)}=171.1, p<$ 0.001; Bonferroni post hoc test $t=10.18, \mathrm{df}=23, p<0.001)$ and PSD-95 (59.75 $\pm 4.3 \%$; two-way ANOVA including withdrawal and L-DOPA treatment as factors: effect of withdrawal $F_{(1,23)}=$ $4.43, p=0.0464$; Bonferroni post hoc test $t=4.671, \mathrm{df}=23, p<$ 0.001 ) relative to CTRL rats (Fig. $3 d, e$ ).

We then evaluated whether restoring DA signaling during withdrawal might also retrieve the disarranged architecture of the MSN synaptic triad in the NAc shell. Notably, the acute treatment with the DA precursor L-DOPA (6 mg/kg, s.c., plus benserazide $6 \mathrm{mg} / \mathrm{kg}$, s.c.) within the first $12 \mathrm{~h}$ abstinence and $1 \mathrm{~h}$ before rats were killed, proved efficacy in: selectively expanding the density of long-thin spines to similar values as controls (two-way
ANOVA including withdrawal and L-DOPA treatment as factors: effect of L-DOPA $F_{(1,23)}=11.28, p=0.0027$; Bonferroni post hoc test $t=5.906, \mathrm{df}=23, p<0.001)$, restoring the immunolabeling for PSD-95 in the NAc (two-way ANOVA including withdrawal and L-DOPA treatment as factors: effect of L-DOPA $F_{(1,23)}=$ 26.66, $p<0.001$; Bonferroni post hoc test $t=7.313, \mathrm{df}=23, p<$ 0.001 ) and increasing TH levels in DA efferent projections (twoway ANOVA including withdrawal and L-DOPA treatment as factors: effect of L-DOPA $F_{(1,23)}=6.034, p=0.022$; Bonferroni post hoc test $t=2.99, \mathrm{df}=23, p<0.05$; Fig. $3 b-e)$.

\section{Long-term synaptic plasticity}

Our functional analysis has confirmed previous evidence showing that, in association with changes in dendritic spine density, TH immunoreactivity and postsynaptic PSD 95 expression, alcohol withdrawal dramatically and selectively decreases the formation of LTD (Spiga et al., 2014). In particular, in single voltage-clamped MSNs of the NAc shell, NMDAR-dependent LTD, induced by LFS ( 500 stimuli at $1 \mathrm{~Hz}$ ) paired with membrane depolarization $(-50 \mathrm{mV})$, was almost completely abolished when tested $12 \mathrm{~h}$ after termination of EtOH exposure (Fig. $4 a-d$ ). We here extend this finding by showing that the loss of LTD formation was long-lasting as it was still apparent when tested after $48 \mathrm{~h}$ and up to $14 \mathrm{~d}$ of withdrawal $\left[F_{(3,31)}=10.05 ; p=\right.$ 0.0001; Bonferroni's post hoc test, CTRL vs EtOH-WDL (12 h) $p=0.0005$, CTRL vs EtOH-WDL $(48 \mathrm{~h}) p=0.0004$, CTRL vs EtOH-WDL (14 d) $p=0.0006$; Fig. $4 a-d]$. In a more detailed evaluation of data obtained in EtOH-WDL (12 h) compared with 
a

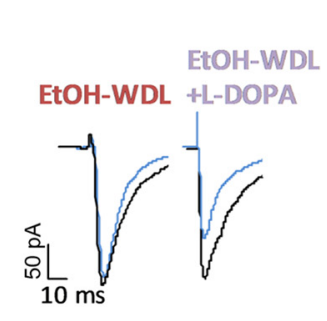

d

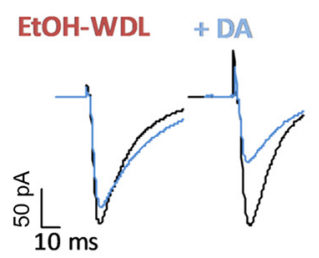

b

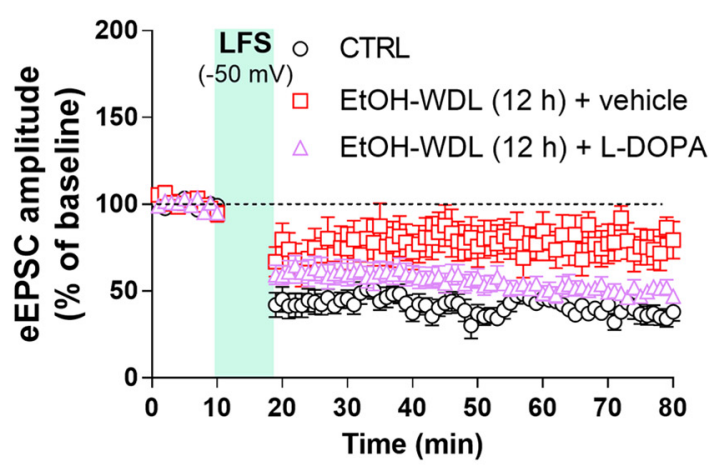

e

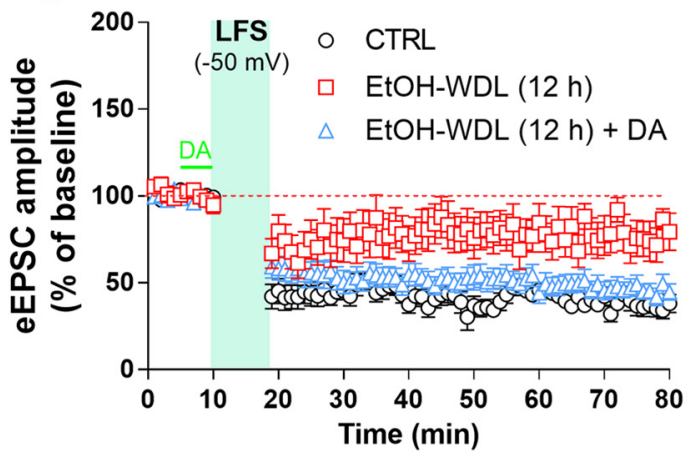

C

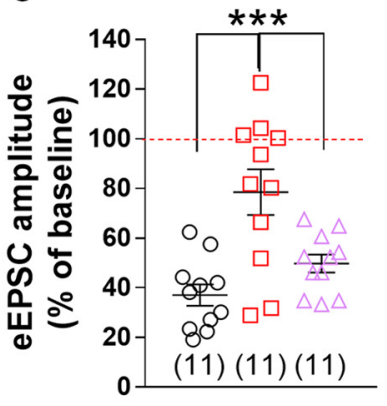

f

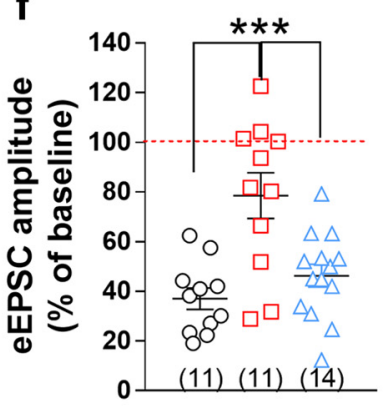

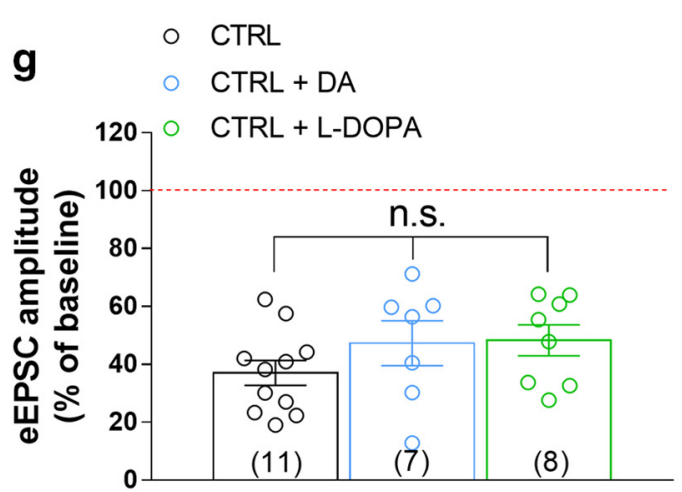

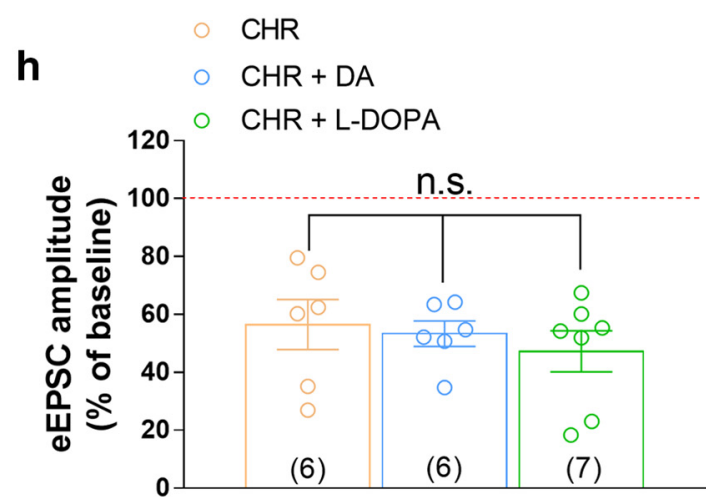

Figure 5. Single acute administration of L-DOPA and bath perfusion of NAc slices with DA restores the hampered LTD formation in NAc shell MSNs from EtOH-withdrawn rats. $\boldsymbol{a}$, Representative EPSCs recorded before (black trace) and $60 \mathrm{~min}$ after (blue trace) LFS paired with depolarization ( $-50 \mathrm{mV}$ ) obtained in single MSNs from (TRL and Et0H-dependent rats that were tested after $12 \mathrm{~h}$ withdrawal. EtOH-WDL rats were subjected to an acute administration of L-DOPA $(6 \mathrm{mg} / \mathrm{kg}, \mathrm{s} . c$.$) and benserazide (6 \mathrm{mg} / \mathrm{kg}$, s.c.), or vehicle, $1 \mathrm{~h}$ before their kill. $\boldsymbol{b}$, Scatter plot graph of the changes in EPSC amplitude with data expressed as percentage of baseline. $\boldsymbol{c}$, Scatter graph illustrating the distribution of individual data, averaged in $\boldsymbol{b}$, calculated by averaging the EPSC amplitude values measured $50-60 \mathrm{~min}$ after LFS and expressed as percentage of baseline. The number of cells analyzed is indicated in each group and were obtained from five animals per group. ${ }^{* * *} p=0.0002$. d, Representative EPSCs recorded before (black trace) and $60 \mathrm{~min}$ after (blue trace) LFS paired with depolarization ( $-50 \mathrm{mV}$ ) obtained in single MSNs from EtOH-dependent rats that were tested after $12 \mathrm{~h}$ of EtOH-WDL. Slices from EtOH-WDL rats were acutely perfused with dopamine (10 $\mu \mathrm{m}) 5$ min before application of LFS (indicated in green in graph $\boldsymbol{e}$ ). $\boldsymbol{e}$, Scatter plot graph of the changes in EPSC amplitude with data expressed as percentage of baseline. $\boldsymbol{f}$, Scatter graph illustrating the distribution of individual data averaged in $\boldsymbol{e}$. The number of cells analyzed is indicated in each group and were obtained from five animals per group. ${ }^{* * *} p=0.0002$. A single intraperitoneal injection of L-DOPA or DA perfusion in slice did not alter LTD formation in NAc shell MSNs from CTRL $(\boldsymbol{g})$ or EtOH-CHR $(\boldsymbol{h})$ rats. The bar graphs illustrate the degree of LTD, calculated by averaging the EPSC amplitude values measured 50-60 min after LFS and expressed as percentage of baseline. The number of cells analyzed is indicated in each group and were obtained from five animals per group.

CTRL group, the scatter graph in Figure $4 d$ shows that the abolishment of LTD is present in $\sim$ one-half of the cells tested ( 6 of 11 tested; Fig. 4d).

Glutamatergic excitatory neurotransmission in MSNs of the NAc shell is heavily controlled by DAergic afferents coming from the VTA (Russo and Nestler, 2013). Because the immunolabeling of TH is markedly reduced in EtOH-WDL rats (present data and Spiga et al., 2014), consistent with the idea of a "hypodopaminergic state" associated with EtOH withdrawal (Melis et al., 2005), we tested the capability of the in vivo L-DOPA treatment of
EtOH-dependent rats, in restoring the hampered long-term plasticity observed at glutamatergic synapses. L-DOPA $(6 \mathrm{mg} / \mathrm{kg}$, s.c.) and benserazide $(6 \mathrm{mg} / \mathrm{kg}$, s.c.) treatment, administered $1 \mathrm{~h}$ before the kill of EtOH-WDL rats, restored LTD formation (50 \pm $4.0 \%$ of BSL) to a value similar to that found in CTRL animals $\left(F_{(2,30)}=11.58, p=0.0002\right.$; Bonferroni's post hoc test, CTRL vs EtOH-WDL 0.0002, EtOH-WDL VS EtOH-WDL + L -DOPA 0.0084; Fig. $5 a-c$ ), but failed to modify LTD formation in either CTRL and EtOH-CHR rats (Fig. $5 g, h$ ). To further explore the effects of increasing DAergic signaling in the NAc of EtOH with- 
a

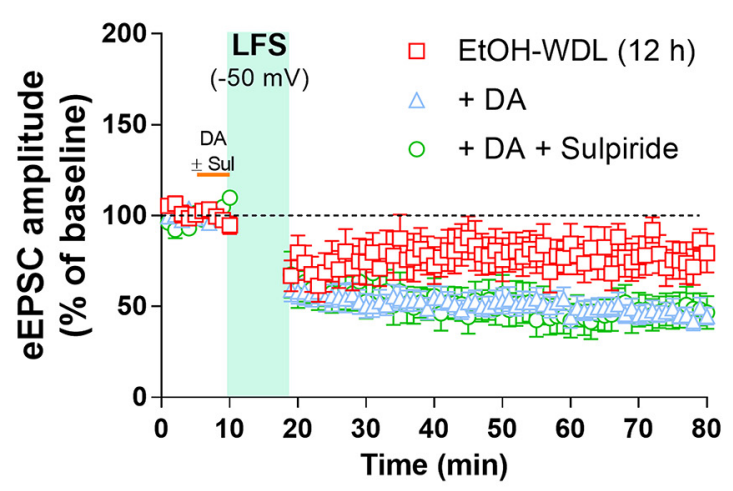

b

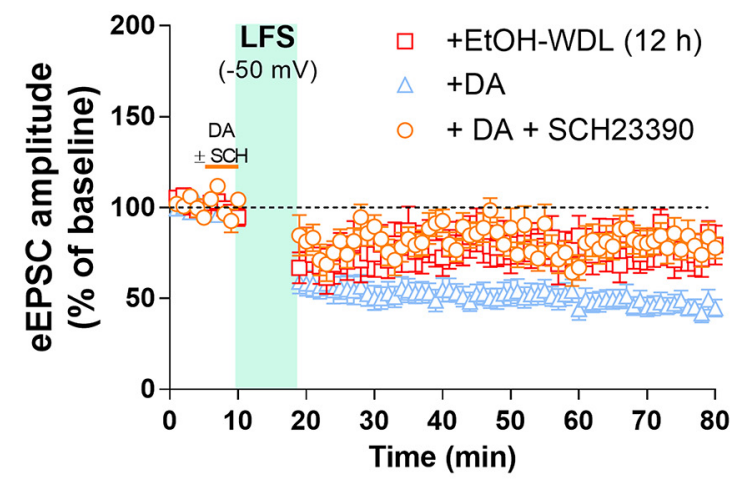

\section{C $\bigcirc$ CTRL \\ $\circ$ EtOH-WDL (12h) $\bigcirc$ EtOH-WDL+DA+Sulp. \\ $\circ \mathrm{EtOH}-\mathrm{WDL}+\mathrm{DA}+\mathrm{SCH}$}

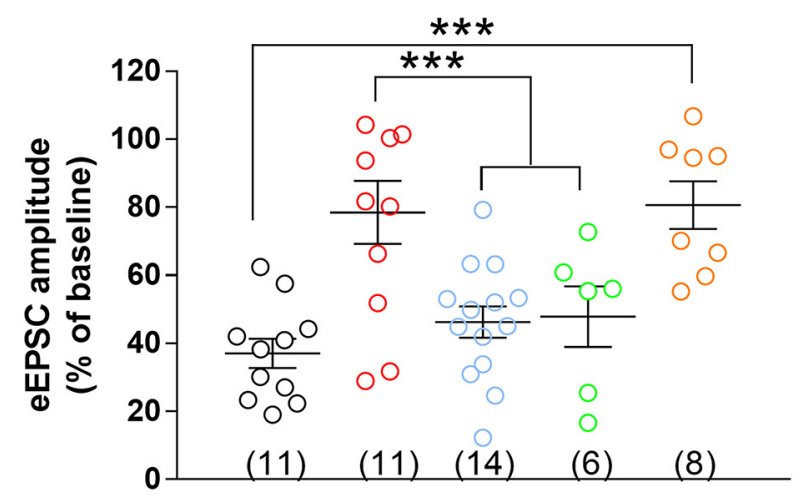

Figure 6. Single acute administration of L-DOPA and bath perfusion of NAc slices with DA restore the decrease in NMDA/AMPA ratio in NAc shell MSNs from EtOH-withdrawn rats. $\boldsymbol{a}$, Representative EPSCs mediated by NMDA and AMPA receptors recorded in single MSNs clamped at $-70 \mathrm{mV}$ (for AMPA) and $+40 \mathrm{mV}$ (for NMDAR in the presence of NBQX $5 \mu \mathrm{M}$ ) from the different experimental groups. $\boldsymbol{b}$, The graph summarizes the NMDAR/AMPAR ratio obtained from MSNs of the different groups. $\boldsymbol{c}$, Scatter graph illustrating the distribution of individual data averaged in $a$ and $b$. The number of cells analyzed is indicated in each graph bar and were obtained from five animals per group. ${ }^{* * *} p=0.0001$.

drawn rats, in a different set of experiments brain slices containing the NAc shell, obtained from animals of the different experimental groups, were bath-perfused with $10 \mu \mathrm{M}$ DA (Lavin and Grace, 2001) for 5 min before the application of LFS. DA perfusion completely rescued LTD formation ( $46 \pm 4 \%$ of BSL) in slices obtained from EtOH-WDL animals (Fig. $5 d-f ; F_{(2,33)}=$ $11.45, p=0.0002$; Bonferroni's post hoc test, CTRL vs EtOHWDL $p=0.0016$, EtOH-WDL VS EtOH-WDL + DA $p=0.0019$, CTRL vs EtOH-WDL + DA $p=0.999)$, but did not alter significantly the extent of LTD in slices from either CTRL and EtOHCHR rats (Fig. $5 g, h$ ).

A recent study by Yagishita et al. (2014), reported that synaptically released DA was able to empower Hebbian plasticity of D1-positive MSNs in the NAc core by an enlargement of dendritic spine heads within $1 \mathrm{~s}$, and a decay of few seconds. Taking advantage of such findings, to evaluate whether WDL-induced effect may be related to a specific sensitivity of D1 or D2 containing neurons in the NAc shell, we bath-applied DA $(10 \mu \mathrm{M})$ in the presence of the D1 and D2 receptor antagonists $\mathrm{SCH} 23390$ and sulpiride, respectively. Figure 6 shows that coperfusion of SCH23390, but not sulpiride, fully prevented the capacity of DA to restore LTD formation in EtOH-WDL rats $\left(F_{(4,45)}=8.86, p=\right.$ 0.0001; Bonferroni's post hoc test, EtOH-WDL vs EtOH-WDL + $\mathrm{DA} p=0.0049$, EtOH-WDL vs EtOH-WDL $+\mathrm{DA}+\mathrm{SCH} p=$ 0.8446, EtOH-WDL vs EtOH-WDL + DA + Sulpiride $p=$
0.0049), indicating that D1 receptors are selectively involved in the restoring effect of DA on LTD formation in EtOH-WDL $(12 \mathrm{~h})$ rats. The scatter graph in Figure $6 c$ shows that the different distribution of WDL-induced impairment in LTD formation is still apparent in the presence of D1 antagonist SCH but not with D2 antagonist sulpiride, where all cell tested showed a consistent LTD formation. In addition, both in vivo L-DOPA treatment and bath-perfusion of NAc slices with DA reversed the reduction in NMDAR/AMPAR ratio in EtOHWDL rats (Spiga et al., 2014) to a value similar to CTRL animals $\left(F_{(3,317)}=14.56, p=0.0001\right.$; Bonferroni's post hoc test, CTRL vs EtOH-WDL $p=0.0001$, EtOH-WDL VS EtOH$\mathrm{WDL}+\mathrm{L}-\mathrm{DOPA} p=0.0001$, EtOH-WDL VS EtOH$\mathrm{WDL}+\mathrm{DA} p=0.0001 ;$ Fig. 7 ).

\section{In vivo microdialysis studies}

Our neurochemical analysis confirmed previous evidence indicating that $\mathrm{EtOH}$ withdrawal is associated with a marked reduction in DA levels (Diana et al., 1993). Indeed, basal DA extracellular levels in the NAc shell of EtOH-WDL and CTRL rats, assessed by in vivo microdialysis, were respectively $48.9 \pm 4$ and $99.36 \pm 7$ (mean \pm SEM; $N=4$ ), expressed as fmol/20 $\mu \mathrm{l}$ sample. In particular, the RM two-way ANOVA on basal DA levels, including ethanol withdrawal as the between-subject factor and time as the repeated-measure factor, showed a significant 
a
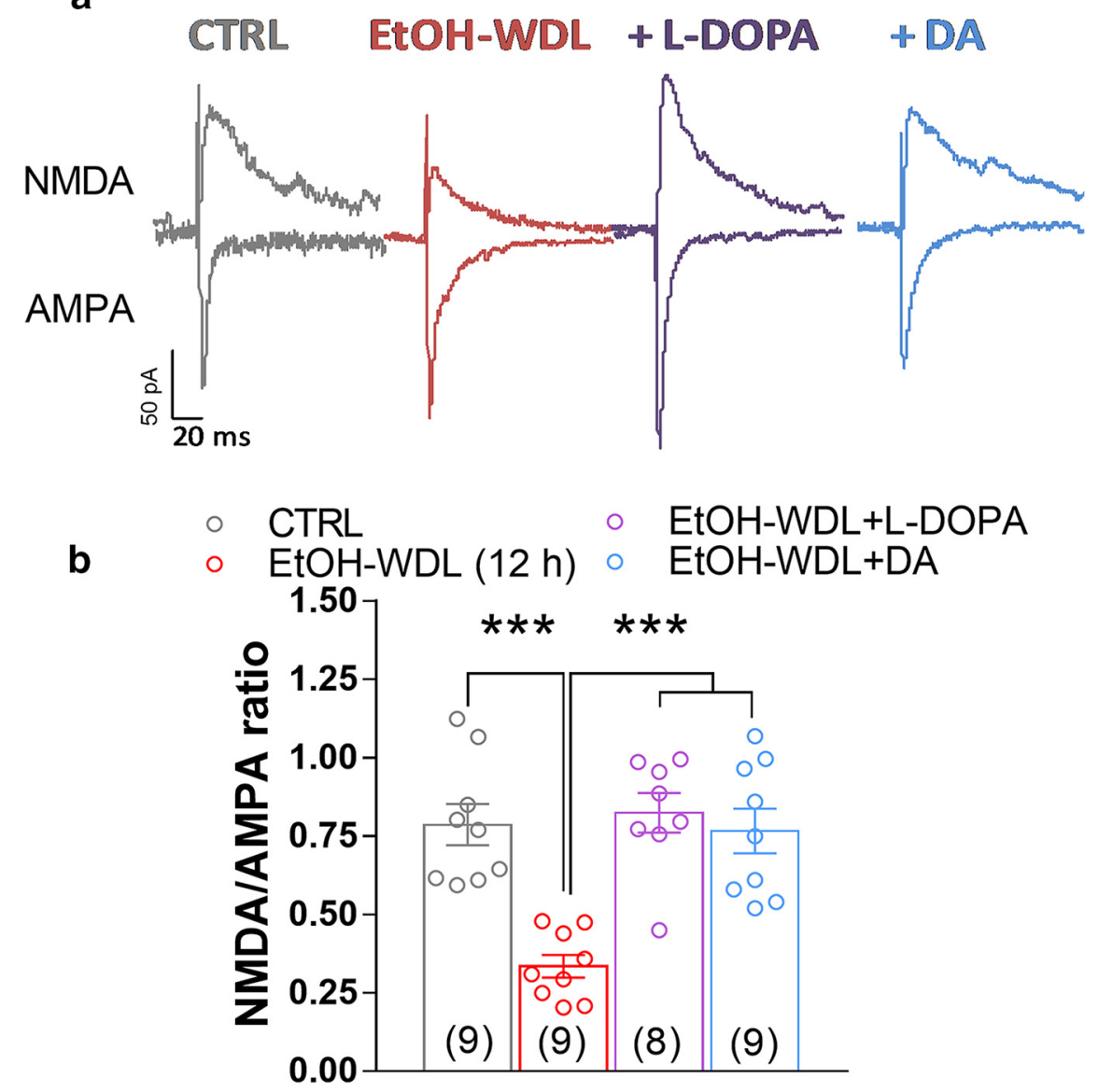

Figure 7. The selective antagonist of $D 1$ but not $D 2$ receptors prevents the restoring effect of DA on LTD levels in EtOH-WDL $(12 \mathrm{~h})$ rats. NAc slices of EtOH-WDL rats were bath-perfused with DA $(10 \mu \mathrm{M})$, in the absence or presence of SCH23390 $(10 \mu \mathrm{M})$ or sulpiride $(10 \mu \mathrm{M})$, for 5 min prior LFS paired with depolarization $(-50 \mathrm{mV}) . \boldsymbol{a}, \boldsymbol{b}$, Scatter plot graph of the changes in EPSC amplitude with data expressed as percentage of baseline. $c$, The scatter graph illustrates the degree of LTD, as in graphs $\boldsymbol{a}$ and $\boldsymbol{b}$, and were obtained from five animals. The number of cells analyzed is indicated for each experimental group. ${ }^{* * *} p=0.0006$.

main effect of ethanol withdrawal $\left(F_{(1,6)}=44.54, p=0.0005\right)$ with no effects of time $\left(F_{(2,12)}=1.192, p=0.3371\right)$ or their interaction $\left(F_{(2,12)}=0.7624, p=0.4879\right.$; Fig. $\left.8 a\right)$.

To study the effects of L-DOPA on the hypodopaminergic state of the NAc in ethanol withdrawal, the time course of extracellular DA levels in NAc shell of EtOH-WDRL (12 h) and CTRL rats following L-DOPA/benserazide administration $(6 / 6 \mathrm{mg} / \mathrm{kg}$, s.c.) was monitored. As shown in Figure 8a, L-DOPA/benserazide administration increased extracellular DA level in EtOH-WDL rats, up to CTRL's levels. In more detail, the RM two-way ANOVA on DA levels following the L-DOPA/benserazide administration, including ethanol withdrawal as the between-subject factor and time as the repeated-measure factor, showed a significant main effect of ethanol withdrawal $\left(F_{(1,6)}=6.207, p=\right.$ $0.0471)$ and time $\left(F_{(9,54)}=2.410, p=0.0223\right)$ but not of their interaction $\left(F_{(9,54)}=1.426, p=0.2003\right)$. When Sidak's multiplecomparisons test was considered, it indicated that EtOH-WDL group differed from CTRL only at the time point 0 , when the L-DOPA administration occurred $(t=3.234, p<0.05, \mathrm{df}=60$; Fig. 8a).

Notably, when DA levels were expressed as percentage of baseline, RM two-way ANOVA on DA levels following L-DOPA administration showed a main effect of group $\left(F_{(1,6)}=13.41 ; p<\right.$ $0.05)$, and time $\left(F_{(9,54)}=3.15 ; p<0.05\right)$, and a significant group $\times$ time interaction $\left(F_{(9,54)}=3.25\right.$; $p<0.05)$. Tukey's post hoc tests showed a larger increase of dialysate DA in the NAc shell of EtOh-WDRL (12 h) compared with basal (filled symbols, $t=5.564, p<$ $0.001, \mathrm{df}=54 ; t=4.490, p<0.001, \mathrm{df}=$ $54)$ and to dialysate DA in the NAc shell of CTRL rats (40 min: $t=4.837, p<0.001$, $\mathrm{df}=60 ; 60 \mathrm{~min}: t=3.984, p<0.01, \mathrm{df}=$ 60; Fig. 8b).

\section{Discussion}

This research took advantage of a multidisciplinary approach aimed to visualize, in alcohol-dependent rats, the structural, functional, and behavioral outcomes of alcohol withdrawal as a tridimensional unicum, a whole (mal)adaptive process, which recognizes in the hypodopaminergic state a causal mechanistic basis. The principal finding consists in the recovery of alcohol withdrawal-associated abnormal limbic memory and synaptic plasticity, by strengthening DA transmission with acute L-DOPA administration.

Aberrant aversive limbic memory
Alcohol-related impairment of aversive
memories could positively bias a drinker's
memory of past negative drinking epi-
sodes, and this, in turn, may increase the
likelihood of future alcohol consumption.
Thus, it was our first requirement to de-
termine in alcohol-dependent rats how
withdrawal affects aversive limbic mem-
ory, a complex function that integrates the
consciously accessible explicit- and the
unconscious implicit memory. Our evi-
dence suggests that experience-dependent
plasticity in the NAc during alcohol withdrawal is associated to defects in neural circuitries that normally serve fear-related learning. Indeed whereas control- and chronically alcohol exposed-rats avoided the fear-conditioned cue and displayed conditioned object-place aversion in the EOR test, alcohol-withdrawn rats displayed a disrupted processing of emotionally salient information, notwithstanding the absence of sensory/motor impairment.

Impairment in learning, memory, and recognition are reported in humans during alcohol withdrawal (Parsons and Nixon, 1993; Smith and Atkinson, 1995); alcoholic patients and binge drinkers (Stephens and Duka, 2008) display reduced galvanic skin responses to a fear conditioned tone (Stephens et al., 2005) and, when presented with fearful facial expressions, show inaccurate fear recognition (Townshend and Duka, 2003).

In agreement with the human data, alcohol withdrawal severely disrupts fear conditioning in mice in a Pavlovian paradigm (Kitaichi et al., 1995). In the laboratory setting, Pavlovian fear conditioning represents the quintessential method of investigating implicit emotional learning (LeDoux, 1996). Nevertheless, it is accompanied by some limitations including (Antoniadis and McDonald, 1999): the assessment of single responses of fear as a measure of implicit memory; the use of nondiscriminative paradigms; the association between the unconditioned stimulus and 
a

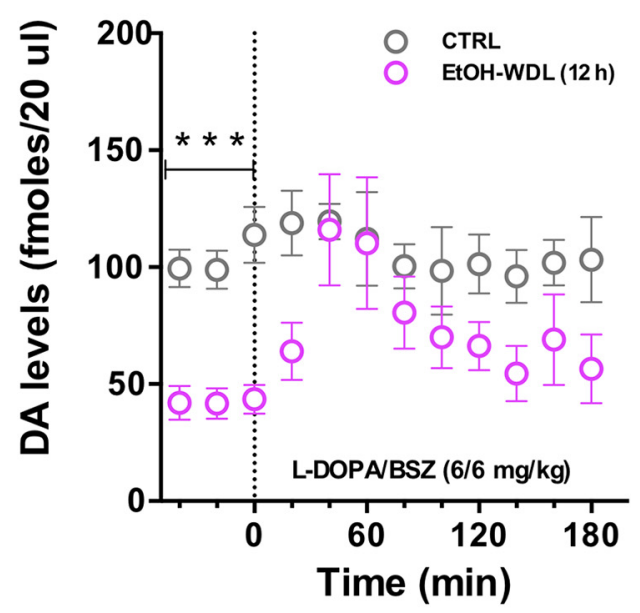

b

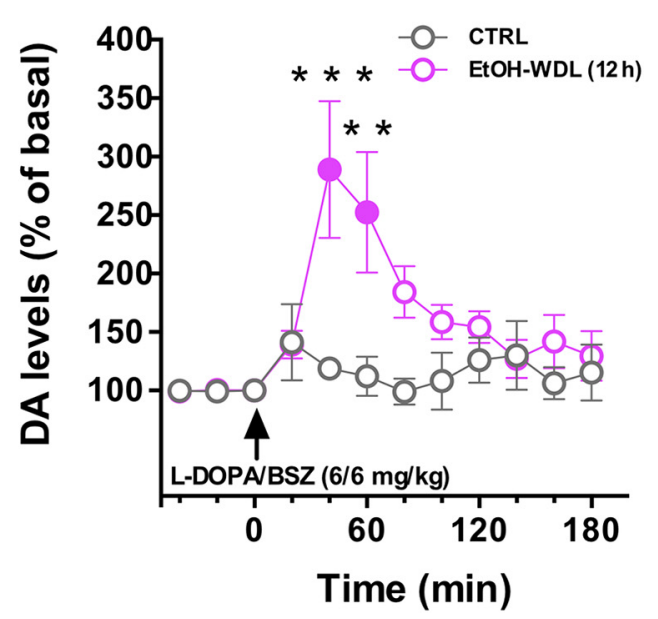

Figure 8. Single acute administration of L-DOPA restores extracellular DA levels in NAc shell of EtOH-withdrawn rats. $\boldsymbol{a}$, EtOH-WDL (12 h) rats displayed lower levels of dialysate DA in the NAc shell, with respect to CTRL rats; L-DOPA/BENSERAZIDE (6/6 mg/kg, s.c.) administration significantly increased DA levels in the NAc shell of EtOH-WDL (12 h) rats, up to CTRL's levels. $\boldsymbol{b}$, Notably, L-DOPA induced a larger increase of dialysate DA in the NAc shell of EtOH-WDRL (12h) compared with basal (filled symbol) and to dialysate DA in the NAc shell of CTRL rats expressed as percentage of baseline. Each value represents the mean $\pm \mathrm{SEM} ; n=4$ rats. ${ }^{* *} p<0.01,{ }^{* * *} p<0.01$.

the environmental context. Rather, the evaluation of limbic memory by the EOR test overcomes these limitations since it implies the recruitment of cognitive networks designed to the encoding and storage of explicit memory representation (objectrecognition), and their integration with the emotional valence of the fear-conditioning, in an unconditioned context. Indeed, memories for emotional situations are not only formed implicitly, as the explicit memory circuits can process their own memories of emotional situations. Notably, dysfunctional aversive limbic memory was still observed after $48 \mathrm{~h}$ and $14 \mathrm{~d}$ of abstinence, highlighting the persistence of defects in the neural circuitries that normally serve fear-related learning.

Aberrant architectural and functional structure of NAc MSNs DA plays a crucial role in the morphological integrity of dendritic spines in MSNs in the NAc (Freund et al., 1984). Decreased DA levels or loss of DA neurons, such as in Parkinson's disease models, reduce the number of dendritic spines (Ingham et al., 1993; Solis et al., 2007; Garcia et al., 2010), whereas increase in DA levels, by cocaine and amphetamine, enhances the number of dendritic spines in MSNs (Robinson and Kolb, 1997, 1999; Li et al., 2003; Lee et al., 2006; Singer et al., 2009). In this study, withdrawal from alcohol consumption induced signs of aberrant plasticity in the NAc, evidenced by the simultaneous visualization of decreased TH and PSD-95 levels, and disarrangement in dendritic spine architecture. The selective loss of thin spines is suggestive of a model in which changes in spine volume and density regulate the anatomy and activity of the mesocorticolimbic network (Nusser et al., 1998; Kharazia and Weinberg, 1999; Matsuzaki et al., 2004; Okamoto et al., 2004). Our functional analysis has indeed provided evidence that, in association with changes in dendritic spine density and synaptic protein expression, alcohol withdrawal virtually abolished NMDAR-dependent LTD as indexed by patch-clamp recordings; moreover, a significant decrease in NMDAR/AMPAR ratio compared with CTRL and EtOH-CHR animals was also observed, likely as a consequence of the marked reduction in NMDAR function. The impaired NMDA-dependent plasticity associated with alcohol withdrawal is consistent with the de- creased immunoreactivity for PSD-95, which plays a crucial role as an anchoring protein for NMDA receptors in the spine membrane (Zhang et al., 2009). Notably, the impairment in LTD paralleled the time course of limbic memory impairment, and persisted until day 14 of withdrawal.

Altogether, these data indicate that in NAc MSNs, alcohol withdrawal-induced DAergic blunting, witnessed by reduced TH expression, impairs NMDAR signaling through the reduced expression of PSD-95 and associated long thin spine loss. This effect in turn may lead to dampening of LTD formation in these synapses and result in dysfunctional aversive limbic memory.

\section{Boosting dopamine transmission}

The aberrant synaptic plasticity observed in the aforementioned conditions might be the cellular background at the core of the inability to correctly process aversive environmental stimuli into salient memory engrams in alcohol-withdrawn rats. This potentially suggests that counteracting the morphological abnormalities recorded in the striatal triad by boosting DA tone during alcohol withdrawal, would shape functional Hebbian plasticity and restore limbic memory. This hypothesis was challenged by injecting withdrawn rats with L-DOPA/benserazide, and monitoring DA release by in vivo microdialysis in the NAc shell. As expected, the downregulated DA release in EtOH-WDL was raised to control rats' values by L-DOPA treatment, with almost $300 \%$ increase from basal levels. Interestingly, DA uprise proved effective in selectively expanding the density of long-thin spines to similar values as controls and produced a reinstatement of the immunolabeling for TH and PSD-95. Notably, the rapid effect of L-DOPA on morphology and PSD-95 immunohistology observed in the present study is consistent with evidence showing that spinogenesis involves fast dynamics (Bresler et al., 2001; Kozorovitskiy et al., 2015). Dopamine stimulation is associated with the recruitment of PSD95 to the postsynaptic density from a diffuse dendritic cytoplasmic pool within 20-60 min (Bresler et al., 2001; Fasano et al., 2013). PSD-95 recruited to the synaptic sites complex with NMDA receptors, increase their signaling thus promoting correct set up of synaptic plasticity mechanisms (Wyneken et al., 2004). In this context, they may serve as key 
determinants in the machinery underlying the interplay between glutamate and dopamine pathways in the striatum (Colledge et al., 2000; Swayze et al., 2004; de Bartolomeis and Tomasetti, 2012). Indeed, the increase in DA availability was also associated to the recovery of withdrawal-related hampered long-term plasticity of the glutamatergic synapse in the triad, with LTD reaching similar values as controls. Further, LTD formation was also rescued in brain slices, obtained from EtOH-WDL animals, in the presence of $10 \mu \mathrm{M}$ DA applied for just 5 min before the induction of LTD. Accordingly, both in vivo L-DOPA treatment and DA bath-perfusion of NAc slices reversed the reduction in NMDAR/AMPAR ratio in EtOHWDL rats to control levels.

Although synaptic plasticity is observed in both D1- and D2-MSNs (Shen et al., 2008), alcohol-induced plasticity is predominantly observed in striatal D1-MSNs, where alcohol consumption affects NMDAR activity (Cheng et al., 2017). Consistently, our data confirm that LTD formation was virtually observed in all the MSNs of CTRL group (Fig. 4d). However in EtOH-WDL rats LTD was apparent in $\sim 40 \%$ of cells tested, suggesting two different populations of cells affected by WDL. The fact that SCH23390, but not sulpiride, completely prevented the capability of DA to restore LTD formation in EtOH-WDL rats, may suggest that MSNs expressing D1are those selectively involved in the aberrant plasticity associated with EtOH-WDL as well as in the restoring effect of DA, strengthening the idea that D1-MSN LTD recovery might be a potential therapeutic strategy for alcohol use (Ma et al., 2018). Overall we suggest that restoring DA levels in the NAc during early alcohol withdrawal reestablishes D1-signaling in the MSN synaptic triad thus normalizing, likely via intraspinous calcium levels (Segal and Andersen, 2000), spine morphology and integrative properties, and revitalizing Hebbian learning. Indeed, DA signaling in the NAc is of exceptional importance for gating attention and facilitating conditioned stimulus associations during fear-conditioning (Pezze and Feldon, 2004; Wise, 2004; Bromberg-Martin et al., 2010). Hence, we assumed that restoring blunted DA signaling and altered connectivity in the NAc before the acquisition phase of the limbic memory task would rescue the impairment in aversive limbic memory here reported. Accordingly, we injected withdrawn rats with $\mathrm{L}-\mathrm{DOPA} / \mathrm{benserazide} 1 \mathrm{~h}$ before the fear-conditioning paradigm at $12 \mathrm{~h}$ abstinence: in addition to the significant reduction in withdrawal symptoms, EtOH-WDL rats displayed acquisition and retrieval of the cue-fear association displaying emotional object-recognition and target-zone avoidance, similar to controls. However, L-DOPA effect was limited to early stages of withdrawal since when injected at $48 \mathrm{~h}$ and $14 \mathrm{~d}$ of abstinence it was ineffective, suggesting that DA replacement can rescue the withdrawn maladaptive synapses just in the early "fluid" and responsive state. Overall this evidence highlights a functional correlation between neuronal and behavioral learning mechanisms in the NAc that, in addition to encoding rewarding experiences, cooperates, as a crucial hub, to the integration of the multiple circuitries that contribute to the formation of limbic memory (Ramirez et al., 2015).

\section{Conclusions}

Alcohol-related impairment in aversive memory of events that occur in the non-laboratory setting could lower the possibility that negative alcohol-related outcomes discourage future consumption; this might explain the disregard of negative drinking-related consequences observed in alcohol-dependent individuals.
Overall our data suggest that strengthening the DA signal, during early withdrawal, may restore the structural architecture of the NAc MSNs triad, presynaptic and postsynaptic indices of functional plasticity that allow those synapses to encode emotionally relevant information and rescue flexibility to the neuronal circuits that process limbic memory formation. Under these conditions, drugs or nonpharmacological tools, such as transcranial magnetic stimulation (Diana et al., 2017) capable of boosting DA signaling (Steensland et al., 2012) during the onset of the withdrawal maladaptive process, could help in breaking the addictive cycle and prove useful in the treatment of alcohol addiction.

\section{References}

Antoniadis EA, McDonald RJ (1999) Discriminative fear conditioning to context expressed by multiple measures of fear in the rat. Behav Brain Res 101:1-13. CrossRef Medline

Berry KP, Nedivi E (2017) Spine dynamics: are they all the same? Neuron 96:43-55. CrossRef Medline

Bosch M, Castro J, Saneyoshi T, Matsuno H, Sur M, Hayashi Y (2014) Structural and molecular remodeling of dendritic spine substructures during long-term potentiation. Neuron 82:444-459. CrossRef Medline

Bourne J, Harris KM (2007) Do thin spines learn to be mushroom spines that remember? Curr Opin Neurobiol 17:381-386. CrossRef Medline

Brancato A, Lavanco G, Cavallaro A, Plescia F, Cannizzaro C (2016) The use of the emotional-object recognition as an assay to assess learning and memory associated to an aversive stimulus in rodents. J Neurosci Methods 274:106-115. CrossRef Medline

Bresler T, Ramati Y, Zamorano PL, Zhai R, Garner CC, Ziv NE (2001) The dynamics of SAP90/PSD-95 recruitment to new synaptic junctions. Mol Cell Neurosci 18:149-167. CrossRef Medline

Bromberg-Martin ES, Matsumoto M, Hikosaka O (2010) Dopamine in motivational control: rewarding, aversive, and alerting. Neuron 68:815-834. CrossRef Medline

Carr DB, Sesack SR (1996) Hippocampal afferents to the rat prefrontal cortex: synaptic targets and relation to dopamine terminals. J Comp Neurol 369:1-15. CrossRef Medline

Cheng Y, Huang CCY, Ma T, Wei X, Wang X, Lu J, Wang J (2017) Distinct synaptic strengthening of the striatal direct and indirect pathways drives alcohol consumption. Biol Psychiatry 81:918-929. CrossRef Medline

Colledge M, Dean RA, Scott GK, Langeberg LK, Huganir RL, Scott JD (2000) Targeting of PKA to glutamate receptors through a MAGUK-AKAP complex. Neuron 27:107-119. CrossRef Medline

Darvas M, Fadok JP, Palmiter RD (2011) Requirement of dopamine signaling in the amygdala and striatum for learning and maintenance of a conditioned avoidance response. Learn Mem 18:136-143. CrossRef Medline

de Bartolomeis A, Tomasetti C (2012) Calcium-dependent networks in dopamine-glutamate interaction: the role of postsynaptic scaffolding proteins. Mol Neurobiol 46:275-296. CrossRef Medline

Diana M, Pistis M, Carboni S, Gessa GL, Rossetti ZL (1993) Profound decrement of mesolimbic dopaminergic neuronal activity during ethanol withdrawal syndrome in rats: electrophysiological and biochemical evidence. Proc Natl Acad Sci U S A 90:7966-7969. CrossRef Medline

Diana M, Raij T, Melis M, Nummenmaa A, Leggio L, Bonci A (2017) Rehabilitating the addicted brain with transcranial magnetic stimulation. Nat Rev Neurosci 18:685-693. CrossRef Medline

Fasano C, Bourque MJ, Lapointe G, Leo D, Thibault D, Haber M, Kortleven C, Desgroseillers L, Murai KK, Trudeau LÉ (2013) Dopamine facilitates dendritic spine formation by cultured striatal medium spiny neurons through both D1 and D2 dopamine receptors. Neuropharmacology 67: 432-443. CrossRef Medline

Freund TF, Powell JF, Smith AD (1984) Tyrosine hydroxylase-immunoreactive boutons in synaptic contact with identified striatonigral neurons, with particular reference to dendritic spines. Neuroscience 13:11891215. CrossRef Medline

Garcia BG, Neely MD, Deutch AY (2010) Cortical regulation of striatal medium spiny neuron dendritic remodeling in parkinsonism: modulation of glutamate release reverses dopamine depletion-induced dendritic spine loss. Cereb Cortex 20:2423-2432. CrossRef Medline

Gass JT, Olive MF (2008) Glutamatergic substrates of drug addiction and alcoholism. Biochem Pharmacol 75:218-265. CrossRef Medline 
Heilig M, Egli M, Crabbe JC, Becker HC (2010) Acute withdrawal, protracted abstinence and negative affect in alcoholism: are they linked? Addict Biol 15:169-184. CrossRef Medline

Hyman SE, Malenka RC, Nestler EJ (2006) Neural mechanisms of addiction: the role of reward-related learning and memory. Annu Rev Neurosci 29:565-598. CrossRef Medline

Ingham CA, Hood SH, van Maldegem B, Weenink A, Arbuthnott GW (1993) Morphological changes in the rat neostriatum after unilateral 6-hydroxydopamine injections into the nigrostriatal pathway. Exp Brain Res 93:17-27. CrossRef Medline

Kalivas PW, Volkow ND (2011) New medications for drug addiction hiding in glutamatergic neuroplasticity. Mol Psychiatry 16:974-986. CrossRef Medline

Kasai H, Fukuda M, Watanabe S, Hayashi-Takagi A, Noguchi J (2010) Structural dynamics of dendritic spines in memory and cognition. Trends Neurosci 33:121-129. CrossRef Medline

Kauer JA, Malenka RC (2007) Synaptic plasticity and addiction. Nat Rev Neurosci 8:844-858. CrossRef Medline

Kharazia VN, Weinberg RJ (1999) Immunogold localization of AMPA and NMDA receptors in somatic sensory cortex of albino rat. J Comp Neurol 412:292-302. CrossRef Medline

Kiefer F, Dinter C (2013) New approaches to addiction treatment based on learning and memory. Curr Top Behav Neurosci 13:671-684. CrossRef Medline

Kitaichi K, Minami Y, Amano M, Yamada K, Hasegawa T, Nabeshima T (1995) The attenuation of suppression of motility by triazolam in the conditioned fear stress task is exacerbated by ethanol in mice. Life Sci 57:743-753. CrossRef Medline

Koob GF, LeMoal M (2001) Drug addiction, dysregulation of reward, and allostasis. Neuropsychopharmacology 24:97-129. CrossRef Medline

Koob GF, Volkow ND (2010) Neurocircuitry of addiction. Neuropsychopharmacology 35:217-238. CrossRef Medline

Kozorovitskiy Y, Peixoto R, Wang W, Saunders A, Sabatini BL (2015) Neuromodulation of excitatory synaptogenesis in striatal development. Elife 4:e10111. CrossRef Medline

Lavin A, Grace AA (2001) Stimunlation of D1-type dopamine receptors enhances excitability in prefrontal cortical pyramidal neurons in a statedependent manner. Neuroscience 104:335-346. CrossRef Medline

LeDoux J (1996) Emotional networks and motor control: a fearful view. Prog Brain Res 107:437-446. CrossRef Medline

Lee KW, Kim Y, Kim AM, Helmin K, Nairn AC, Greengard P (2006) Cocaine-induced dendritic spine formation in D1 and D2 dopamine receptor-containing medium spiny neurons in nucleus accumbens. Proc Natl Acad Sci U S A 103:3399-3404. CrossRef Medline

Lendvai B, Stern EA, Chen B, Svoboda K (2000) Experience-dependent plasticity of dendritic spines in the developing rat barrel cortex in vivo. Nature 404:876-881. CrossRef Medline

Li Y, Kolb B, Robinson TE (2003) The location of persistent amphetamineinduced changes in the density of dendritic spines on medium spiny neurons in the nucleus accumbens and caudate-putamen. Neuropsychopharmacology 28:1082-1085. CrossRef Medline

Ma T, Cheng Y, Roltsch Hellard E, Wang X, Lu J, Gao X, Huang CCY, Wei XY, Ji JY, Wang J (2018) Bidirectional and long-lasting control of alcoholseeking behavior by corticostriatal LTP and LTD. Nat Neurosci 21:373383. CrossRef Medline

Matsuzaki M, Honkura N, Ellis-Davies GC, Kasai H (2004) Structural basis of long-term potentiation in single dendritic spines. Nature 429:761-766. CrossRef Medline

Melis M, Spiga S, Diana M (2005) The dopamine hypothesis of drug addiction: hypodopaminergic state. Int Rev Neurobiol 63:101-154. CrossRef Medline

Nestler EJ (2013) Cellular basis of memory for addiction. Dialogues Clin Neurosci 15:431-443. Medline

Nikolaus S, Beu M, de Souza Silva MA, Huston JP, Hautzel H, Mattern C, Antke C, Müller HW (2016) Relationship between L-DOPA-induced reduction in motor and exploratory activity and striatal dopamine D2 receptor binding in the rat. Front Behav Neurosci 9:352. CrossRef Medline

Nusser Z, Lujan R, Laube G, Roberts JD, Molnar E, Somogyi P (1998) Cell type and pathway dependence of synaptic AMPA receptor number and variability in the hippocampus. Neuron 21:545-559. CrossRef Medline
Okamoto K, Nagai T, Miyawaki A, Hayashi Y (2004) Rapid and persistent modulation of actin dynamics regulates postsynaptic reorganization underlying bidirectional plasticity. Nat Neurosci 7:1104-1112. CrossRef Medline

Parsons OA, Nixon SJ (1993) Neurobehavioral sequelae of alcoholism. Neurol Clin 11:205-218. CrossRef Medline

Paxinos G, Watson C (1998) The rat brain in stereotaxic coordinates, Ed 4. London: Academic.

Pezze MA, Feldon J (2004) Mesolimbic dopaminergic pathways in fear conditioning. Prog Neurobiol 74:301-320. CrossRef Medline

Pignatelli M, Umanah GKE, Ribeiro SP, Chen R, Karuppagounder SS, Yau HJ, Eacker S, Dawson VL, Dawson TM, Bonci A (2017) Synaptic plasticity onto dopamine neurons shapes fear learning. Neuron 93:425-440. CrossRef Medline

Ramirez S, Liu X, MacDonald CJ, Moffa A, Zhou J, Redondo RL, Tonegawa S (2015) Activating positive memory engrams suppresses depression-like behaviour. Nature 522:335-339. CrossRef Medline

Robinson TE, Kolb B (1997) Persistent structural modifications in nucleus accumbens and prefrontal cortex neurons produced by previous experience with amphetamine. J Neurosci 17:8491-8497. CrossRef Medline

Robinson TE, Kolb B (1999) Alterations in the morphology of dendrites and dendritic spines in the nucleus accumbens and prefrontal cortex following repeated treatment with amphetamine or cocaine. Eur J Neurosci 11:1598-1604. CrossRef Medline

Rothblat DS, Rubin E, Schneider JS (2001) Effects of chronic alcohol ingestion on the mesostriatal dopamine system in the rat. Neurosci Lett 300: 63-66. CrossRef Medline

Russo SJ, Nestler EJ (2013) The brain reward circuitry in mood disorders. Nat Rev Neurosci 14:609-625. CrossRef Medline

Segal M, Andersen P (2000) Dendritic spines shaped by synaptic activity. Curr Opin Neurobiol 10:582-586. CrossRef Medline

Shen W, Flajolet M, Greengard P, Surmeier DJ (2008) Dichotomous dopaminergic control of striatal synaptic plasticity. Science 321:848-851. CrossRef Medline

Singer BF, Tanabe LM, Gorny G, Jake-Matthews C, Li Y, Kolb B, Vezina P (2009) Amphetamine-induced changes in dendritic morphology in rat forebrain correspond to associative drug conditioning rather than nonassociative drug sensitization. Biol Psychiatry 65:835-840. CrossRef Medline

Smith DM, Atkinson RM (1995) Alcoholism and dementia. Int J Addict 30:1843-1869. CrossRef Medline

Solis O, Limón DI, Flores-Hernández J, Flores G (2007) Alterations in dendritic morphology of the prefrontal cortical and striatum neurons in the unilateral 6-OHDA-rat model of Parkinson's disease. Synapse 61:450 458. CrossRef Medline

Spiga S, Talani G, Mulas G, Licheri V, Fois GR, Muggironi G, Masala N, Cannizzaro C, Biggio G, Sanna E, Diana M (2014) Hampered long-term depression and thin spine loss in the nucleus accumbens of ethanoldependent rats. Proc Natl Acad Sci U S A 111:E3745-3754. CrossRef Medline

Steensland P, Fredriksson I, Holst S, Feltmann K, Franck J, Schilström B, Carlsson A (2012) The monoamine stabilizer (-)-OSU6162 attenuates voluntary ethanol intake and ethanol-induced dopamine output in nucleus accumbens. Biol Psychiatry 72:823-831. CrossRef Medline

Stephens DN, Duka T (2008) Cognitive and emotional consequences of binge drinking: role of amygdala and prefrontal cortex. Philos Trans R Soc Lond B Biol Sci 363:3169-3179. CrossRef Medline

Stephens DN, Ripley TL, Borlikova G, Schubert M, Albrecht D, Hogarth L, Duka $\mathrm{T}$ (2005) Repeated ethanol exposure and withdrawal impairs human fear conditioning and depresses long-term potentiation in rat amygdala and hippocampus. Biol Psychiatry 58:392-400. CrossRef Medline

Swayze RD, Lisé MF, Levinson JN, Phillips A, El-Husseini A (2004) Modulation of dopamine mediated phosphorylation of AMPA receptors by PSD-95 and AKAP79/150. Neuropharmacology 47:764-778. CrossRef Medline

Townshend JM, Duka T (2003) Mixed emotions: alcoholics' impairments in the recognition of specific emotional facial expressions. Neuropsychologia 41:773-782. CrossRef Medline

Trachtenberg JT, Chen BE, Knott GW, Feng G, Sanes JR, Welker E, Svoboda K 
(2002) Long-term in vivo imaging of experience-dependent synaptic plasticity in adult cortex. Nature 420:788-794. CrossRef Medline

Uys JD, McGuier NS, Gass JT, Griffin WC 3rd, Ball LE, Mulholland PJ (2016) Chronic intermittent ethanol exposure and withdrawal leads to adaptations in nucleus accumbens core postsynaptic density proteome and dendritic spines. Addict Biol 21:560-574. CrossRef Medline

Weiss F, Parsons LH, Schulteis G, Hyytiä P, Lorang MT, Bloom FE, Koob GF (1996) Ethanol self-administration restores withdrawal-associated deficiencies in accumbal dopamine and 5-hydroxytryptamine release in dependent rats. J Neurosci 16:3474-3485. CrossRef Medline

Wise RA (2004) Dopamine, learning and motivation. Nat Rev Neurosci 5:483-494. CrossRef Medline

Wyneken U, Marengo JJ, Orrego F (2004) Electrophysiology and plasticity in isolated postsynaptic densities. Brain Res Brain Res Rev 47:54-70. CrossRef Medline

Yagishita S, Hayashi-Takagi A, Ellis-Davies GC, Urakubo H, Ishii S, Kasai H (2014) A critical time window for dopamine actions on the structural plasticity of dendritic spines. Science 345:1616-1620. CrossRef Medline

Zhang J, Xu TX, Hallett PJ, Watanabe M, Grant SG, Isacson O, Yao WD (2009) PSD-95 uncouples dopamine-glutamate interaction in the D1/ PSD-95/NMDA receptor complex. J Neurosci 29:2948-2960. CrossRef Medline

Zhou FC, Anthony B, Dunn KW, Lindquist WB, Xu ZC, Deng P (2007) Chronic alcohol drinking alters neuronal dendritic spines in the brain reward center nucleus accumbens. Brain Res 1134:148-161. CrossRef Medline 